\title{
The faint young Sun problem revisited with a 3-D climate-carbon model - Part 1
}

\author{
G. Le Hir ${ }^{1}$, Y. Teitler ${ }^{1, *}$, F. Fluteau ${ }^{1}$, Y. Donnadieu ${ }^{2}$, and P. Philippot ${ }^{1}$ \\ ${ }^{1}$ IPGP, Institut de Physique du Globe de Paris, Sorbonne Paris cité, Université Paris Diderot, UMR7154, 75005, France \\ ${ }^{2}$ LSCE, CNRS-CEA-UVSQ, 91191 Gif-sur-Yvette, France \\ *now at: Centre for Exploration Targeting, University of Western Australia, Crawley, Australia
}

Correspondence to: G. Le Hir (lehir@ipgp.fr)

Received: 6 February 2013 - Published in Clim. Past Discuss.: 22 March 2013

Revised: 17 February 2014 - Accepted: 18 February 2014 - Published: 3 April 2014

\begin{abstract}
During the Archaean, the Sun's luminosity was 18 to $25 \%$ lower than the present day. One-dimensional radiative convective models (RCM) generally infer that high concentrations of greenhouse gases $\left(\mathrm{CO}_{2}, \mathrm{CH}_{4}\right)$ are required to prevent the early Earth's surface temperature from dropping below the freezing point of liquid water and satisfying the faint young Sun paradox (FYSP, an Earth temperature at least as warm as today). Using a one-dimensional (1-D) model, it was proposed in 2010 that the association of a reduced albedo and less reflective clouds may have been responsible for the maintenance of a warm climate during the Archaean without requiring high concentrations of atmospheric $\mathrm{CO}_{2}\left(p \mathrm{CO}_{2}\right)$. More recently, 3-D climate simulations have been performed using atmospheric general circulation models (AGCM) and Earth system models of intermediate complexity (EMIC). These studies were able to solve the FYSP through a large range of carbon dioxide concentrations, from 0.6 bar with an EMIC to several millibars with AGCMs. To better understand this wide range in $p \mathrm{CO}_{2}$, we investigated the early Earth climate using an atmospheric GCM coupled to a slab ocean. Our simulations include the ice-albedo feedback and specific Archaean climatic factors such as a faster Earth rotation rate, high atmospheric concentrations of $\mathrm{CO}_{2}$ and/or $\mathrm{CH}_{4}$, a reduced continental surface, a saltier ocean, and different cloudiness. We estimated full glaciation thresholds for the early Archaean and quantified positive radiative forcing required to solve the FYSP. We also demonstrated why RCM and EMIC tend to overestimate greenhouse gas concentrations required to avoid full glaciations or solve the FYSP. Carbon cycle-climate interplays and conditions for sustaining $p \mathrm{CO}_{2}$ will be discussed in a companion paper.
\end{abstract}

\section{Introduction}

Sagan and Mullen (1972) argued from solar models that, in the early Archaean, the young Sun's luminosity was $25 \%$ lower compared to now. According to climate models, the weakness of the young Sun's brightness would have implied that Earth's surface temperature was well below the freezing point of water during the first two billion years of its history. A completely frozen Earth, however, conflicts with evidence of the presence of liquid water at the surface and life development during the Archaean. More intriguingly, geological evidence suggests that the Archaean climate was similar or even warmer than the present-day climate. Greenhouse gases, and more specifically carbon dioxide, were soon put forward as good candidates for solving this issue known as the "faint young Sun paradox" (FYSP; see Feulner, 2012 for a detailed review). Using a vertical one-dimensional radiative convective climate model (RCM), Kasting $(1984,2010)$ calculated that an atmospheric carbon dioxide partial pressure $\left(p \mathrm{CO}_{2}\right)$ of 0.3 bar or $\sim 1000$ times the preindustrial atmospheric level (PAL) (i.e. $0.28 \mathrm{mbar}$ or $280 \mathrm{ppm}$ ) was needed to maintain a mean global surface temperature of $15{ }^{\circ} \mathrm{C}$ for a Sun $75 \%$ dimmer than today.

In parallel with the modelling approach, atmospheric carbon dioxide concentration was semi-quantitatively estimated from Archaean palaeosols. Considering the absence of siderite in $2.8 \mathrm{Ga}$-old palaeosols, Rye et al. (1995) suggested from thermodynamical modelling that the $p \mathrm{CO}_{2}$ had not exceeded $\sim 0.04$ bar (or $\sim 130 \mathrm{PAL}$ ) during the Late Archaean. Questioning the relevance of the Rye et al. (1995) approach, Sheldon (2006) conducted mass-balance calculations of weathering in several Archaean to Palaeoproterozoic 
palaeosols and proposed that the $p \mathrm{CO}_{2}$ fluctuated from 3 mbar to 26 mbar (i.e. 11 to $93 \mathrm{PAL}$ ) from 2.2 to $1.0 \mathrm{Ga}$. More recently, Driese et al. (2011), using palaeoweathering indicators, suggested moderate $\mathrm{CO}_{2}$ partial pressures of about $10 \mathrm{mbar}$ at $2.7 \mathrm{Ga}$ ago. Given the composition of iron-rich minerals found in Archaean banded iron formations (BIFs), Rosing et al. (2010) argued that the coexistence of magnetite (i.e. $\mathrm{Fe}_{3} \mathrm{O}_{4}$, a moderately oxidised mineral) and siderite (i.e. $\mathrm{FeCO}_{3}$, a reduced mineral) in $\mathrm{BIF}$ was dependent on the atmospheric level in di-hydrogen $\left(\mathrm{pH}_{2}\right)$. Di-hydrogen $\left(\mathrm{H}_{2}\right)$ is a nutrient for methanogenic bacteria, and biological constraints impose a minimum $\mathrm{pH}_{2}$. Using this constraint, Rosing et al. (2010) defined an upper limit for $p \mathrm{CO}_{2}$ of about $0.9 \mathrm{mbar}$ ( $900 \mathrm{ppmv}$ or $3.2 \mathrm{PAL}$ ). Such a low $p \mathrm{CO}_{2}$ has been the core of vivid debate among specialists, notably because BIFs are formed in marine environments far from thermodynamic equilibrium with the atmosphere and therefore are poor proxies of the early Earth atmosphere composition (Dauphas and Kasting, 2011; Reinhard and Planavsky, 2011).

Given the difficulties in estimating the partial pressure of atmospheric greenhouse gases on the primitive Earth, other mechanisms influencing climate such as changes in cloud properties have been explored. The mean forcing of clouds results from two opposite effects (Pierrehumbert, 2010). Clouds are highly reflective in the spectrum of visible solar radiation (shortwave radiation) and highly absorbent in the spectrum of thermal terrestrial radiation (longwave radiation). This leads to two well-known opposite effects; the shortwave reflection effect contributing to the planetary albedo and the longwave absorption effect contributing to the greenhouse. These mechanisms are related to the cloud type, the greenhouse effect being stronger than the albedo effect in the case of cirrus clouds, which are quite transparent at visible wavelengths but good absorbers of thermal terrestrial radiation. Using a one-dimensional radiative model, Goldblatt and Zahnle (2011b) estimated that in order to compensate for a weak Sun, Earth must have been entirely cloud-covered with poorly reflective (i.e. absence of stratus) but 3.5 times thicker clouds than today. In the absence of a mechanism able to change cloud properties in such proportions, the authors concluded that this scenario was highly unlikely. Goldblatt and Zahnle (2011b) also challenged Rosing et al.'s (2010) hypothesis that thinner clouds, caused by sparse cloud condensation nuclei $(\mathrm{CCN})$, could have acted as an alternative to atmospheric greenhouse gases to warm up the early Earth's surface. In the present-day atmosphere, abundant CCN permit the formation of small liquid water droplets, leading to optically dense and highly reflective clouds because of their direct scattering effect (Charlson et al., 1987). During the Archaean, the concentration of CCN would have been about 10 to $20 \%$ of its natural presentday level due to lower organic and inorganic sources. As a consequence, fewer droplets, but of larger size, would have formed optically thin clouds characterised by a low scattering of shortwave radiations and shorter lifetime. This hypothesis had been quantified with RCM simulations (Rosing et al., 2010). However, using a more realistic treatment of clouds, Goldblatt and Zahnle (2011b) demonstrated that the radiative forcing due to such changes in cloud properties has been overestimated.

To go one step further in the understanding of the FYSP, Kienert et al. (2012) conducted the first 3-D climate modelling of the Archaean climate using the EMIC (Earth system models of intermediate complexity) CLIMBER, which consists in an ocean general circulation model coupled with a simplified, low-resolution atmosphere. Using Archaean boundary conditions including a reduced incoming solar radiation, a faster Earth rotation and a reduced continental surface, CLIMBER simulates a present-day climate for a carbon dioxide partial pressure fixed at 0.6 bar. The authors explained their results by the ice-albedo feedback, which is enhanced during the Archaean due to a faster Earth rotation rate. This result contrasts with conclusions obtained by Jenkins (1993b) and Jenkins et al. (1993) with CCMAO (CCMAO was the version of the NCAR model at the beginning of the 90s, an atmospheric GCM coupled to a swamp ocean without heat capacity), where a faster rotation rate would have induced a warmer climate. The recent modelling of Archaean climate by Charney et al. (2013) using LMDz (an atmospheric GCM coupled to a slab ocean developed by Laboratoire de Météorologie Dynamique) challenged the CLIMBER results (Kienert et al., 2012, 2013) and revealed a very limited impact of the faster Earth rotation. However, LMDz results suggest that, for $3.8 \mathrm{Ga}$-old conditions, 100 mbar of carbon dioxide and 2 mbar of $\mathrm{CH}_{4}$ are required to maintain an Earth climate as warm as today. Similar results are predicted for the Late Archaean $(2.7 \mathrm{Ga})$, with the atmospheric GCM coupled to a slab ocean CAM3 (Wolf and Toon, 2013), where a combination of $20 \mathrm{mbar}$ of $\mathrm{CO}_{2}$ and $1 \mathrm{mbar}$ of $\mathrm{CH}_{4}$ is required to yield a global mean surface temperature near that of the present day.

To understand why AGCMs (Charney et al., 2013; Wolf and Toon, 2013; Kunze et al., 2014), EMIC (Kienert et al., 2012, 2013) and RCMs (Rosing et al., 2010; Kasting, 1984) differ in simulating the early Earth climate, we investigated the Precambrian climate using an atmospheric general circulation model coupled to a slab ocean FOAM. The paper is organised as follows. First, we estimate the radiative deficit required for the onset of a pan-glaciation. We run experiments ranging from 3.5 to $1 \mathrm{Ga}$ to explore the impacts of Archaean boundary conditions (solar constant, palaeogeography, amount of emerged continental surface, and cloud properties). Second, we investigate the faint young Sun problem by performing additional sets of simulations where the effects of greenhouse gases $\left(\mathrm{CO}_{2}\right.$ and $\left.\mathrm{CH}_{4}\right)$, saltier oceans, faster Earth rotation or sea ice albedo are tested. Finally, we compare our results with the above-mentioned studies to explore the causes of observed differences among RCMs, 


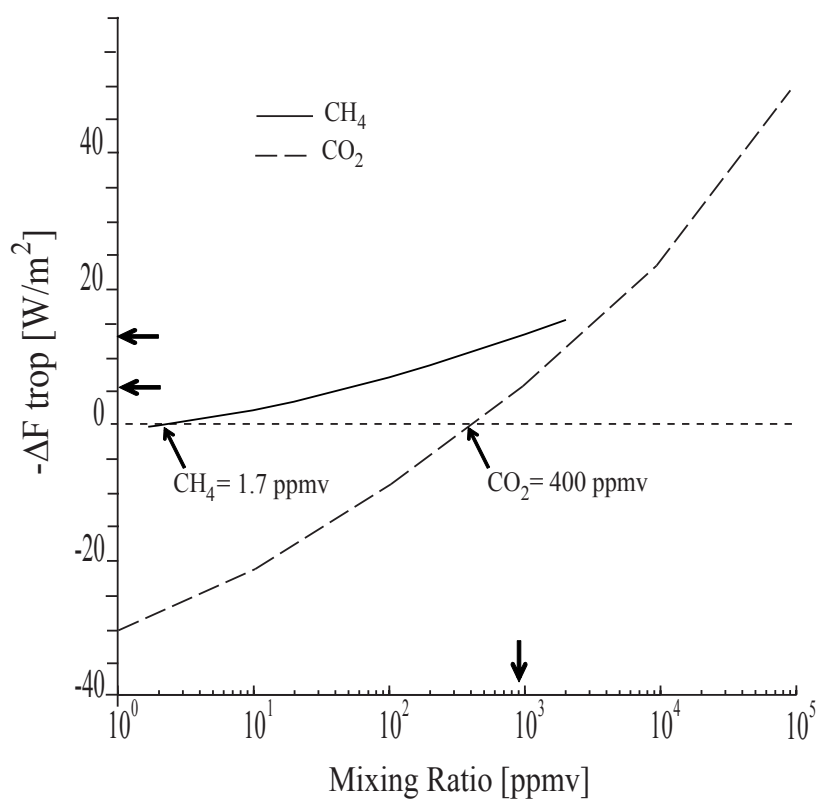

Fig. 1. Net long-wave fluxes computed for $\mathrm{CO}_{2}$ and $\mathrm{CH}_{4}$ with the FOAM radiative code (NCAR ccm3) (the total atmospheric is held constant, 1 bar). Thick arrows indicate the radiative forcing corresponding to 0.9 mbar of $\mathrm{CO}_{2}$ and $\mathrm{CH}_{4}$. Using the present-day atmosphere as a reference, the change in net flux at the tropopause ( $\left.\Delta F_{\text {trop }}\right)$ is $19 \mathrm{~W} \mathrm{~m}^{-2}$, which reduces to 6 and $13 \mathrm{~W} \mathrm{~m}^{-2}$ for 0.9 mbar of $\mathrm{CO}_{2}$ and $\mathrm{CH}_{4}$, respectively.

EMIC and AGCMs, and discuss how these models differ in representing the ice-albedo feedback mechanism.

\section{Model description and simulation specifications}

\subsection{Model description}

Climate simulations were run with the atmospheric general circulation climate model (AGCM) FOAM 1.5. The atmospheric component of FOAM is a parallelised version of NCAR's Community Climate Model 2 (CCM2) with the upgraded radiative and hydrologic physics incorporated in CCM3 v. 3.2 (Jacob, 1997). All simulations were performed with an R15 spectral resolution $\left(4.5^{\circ} \times 7.5^{\circ}\right)$ and 18 vertical levels. The radiative code (extracted from NCAR CCM3) has already shown its validity in atmospheres highly enriched in $\mathrm{CO}_{2}$ (Pierrehumbert, 2004; Le Hir et al., 2010). The infrared absorption has been computed (Fig. 1) to replace $\mathrm{CO}_{2}$ $\mathrm{CH}_{4}$ conversion proposed by Rosing et al. (2010). Under an enriched $\mathrm{CH}_{4}$ atmosphere, no significant differences are observed compared to prior estimates (Kiehl and Dickinson, 1987; Halevy et al., 2009). FOAM integrates the CCM3 version of cloud water parameterisation. As in the CCM3, cloud optical properties and liquid water droplet clouds used the Slingo (1989) parameterisation, where the liquid water droplet clouds (Cloud Water Path or CWP) is determined by integrating the liquid water concentration $\left(q_{\mathrm{clw}}\right)$ :

$\mathrm{CWP}=\int q_{\mathrm{clw}} \cdot \mathrm{d} z$ where $q_{\mathrm{clw}}=q_{\mathrm{clw} 0} e^{\left(-z / H_{\mathrm{clw}}\right)}$

$z$ being the altitude, $q_{\mathrm{clw} 0}$ an empirical constant equals to $0.21 \mathrm{~g} \mathrm{~m}^{-3}$ and $H_{\mathrm{clw}}$ the scale height representing the total precipitable water column, which is dependent of the precipitable water $\left(q_{\text {tot }}\right)$. This last equation implies an exponential decay for in-cloud water concentration,

$H_{\mathrm{clw}}=700 \ln \left(1+q_{\text {tot }}\right)$

with $q_{\text {tot }}$ being computed by integrating the specific humidity $Q$ (in $\mathrm{kg} \mathrm{kg}^{-1}$ ) over $\mathrm{d} p, p$ being the pressure and $g$ the gravitational acceleration $\left(9.8 \mathrm{~m} \mathrm{~s}^{-2}\right)$ :

$q_{-}$tot $=1 / g * \int Q \mathrm{~d} p$.

FOAM is used in mixed-layer mode, meaning the atmospheric model is linked to a $50 \mathrm{~m}$ mixed-layer ocean with heat transport parameterised through diffusion. The diffusive rate of the slab ocean $\left(Q_{\text {flux }}\right)$ is derived from the net surface fluxes and fixed to represent sea ice-covered seas based on estimates of the present-day sea ice mass budget. The sea ice module uses the thermodynamics of NCARs to compute ice fraction (growth and melting), snow cover, and penetrating radiation, and includes a Semtner model to calculate the sea ice temperature. The sea ice module does not treat sea ice dynamics, a lack which may slow the sea ice flow and underestimate the sea ice cover (Voigt and Abbot, 2012). Sea ice albedo is fixed at 0.7 (visible spectrum) and 0.5 (nearinfrared spectrum).

\subsection{Boundary conditions and experimental design}

In this section, we describe boundary conditions used to explore the effects of solar constants, palaeogeography (amount of continental surface), and cloud properties from 3.5 to $1 \mathrm{Ga}$ ago. Sets of simulations are summarised in Table 1.

\subsubsection{Solar irradiance and palaeogeographies}

Following Gough's formula (1981), the solar constant has been increased by $19 \%$, from $3.5 \mathrm{Ga}\left(1053 \mathrm{~W} \mathrm{~m}^{-2}\right)$ to $1 \mathrm{Ga}$ $\left(1258 \mathrm{~W} \mathrm{~m}^{-2}\right)$ (Fig. 2a). Orbital parameters were set at their present-day values (orbital eccentricity: 0.016724, obliquity: 23.4463, vernal equinox latitude of perihelion: 77.9610) in all experiments. We varied the continental surface in response to the crustal growth and emergence, a process which affected the mean surface albedo $\left(\alpha_{\text {ocean }}=0.06, \alpha_{\text {baresoil }}=\right.$ 0.32 ). Different scenarios ranging from a progressive formation to a quasi-instantaneous formation of all continental crust have been proposed (see Lowe and Tice, 2007 for a detailed review). Here we considered a gradual continental growth (Fig. 2b), consistent with the changes of ${ }^{87} \mathrm{Sr} /{ }^{86} \mathrm{Sr}$ 
Table 1. Simulations performed in the Sect. 3 ( $\Delta F_{\text {trop }}$ is held constant and equals to $+19 \mathrm{~W} \mathrm{~m}^{-2}$ ).

\begin{tabular}{|c|c|c|c|c|c|}
\hline \multirow{2}{*}{$\begin{array}{l}\text { set of } \\
\text { simulations }\end{array}$} & \multicolumn{2}{|c|}{ Boundary conditions } & \multirow{2}{*}{$\begin{array}{c}\text { LOD } \\
\text { (hours) }\end{array}$} & \multirow{2}{*}{$\begin{array}{c}\text { Droplet } \\
\operatorname{size}(\mu \mathrm{m})\end{array}$} & \multirow{2}{*}{$\begin{array}{c}\text { seawater } \\
\text { freezing point }\end{array}$} \\
\hline & Paleogeography & Solar constant & & & \\
\hline modern clouds & 3.5-1Ga (Fig. 2b) & 3.5-1Ga (Fig. 2a) & 24 & $5-10$ & $-1.8^{\circ} \mathrm{C}$ \\
\hline no clouds & 6 & “ & 24 & l & “ \\
\hline Large droplet clouds & “6 & “ & 24 & 20 & “6 \\
\hline
\end{tabular}

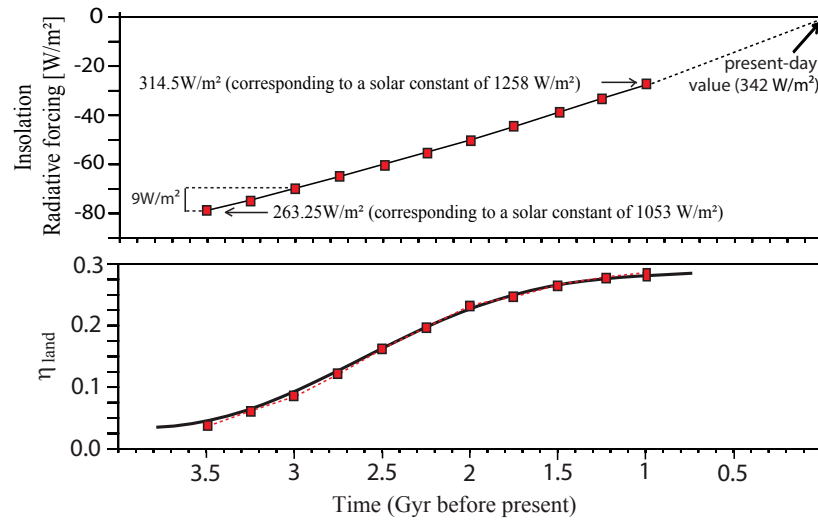

\subsubsection{Radiative forcing by greenhouse gases and ozone amounts}

To set up boundary conditions correctly, we estimated the greenhouse radiative forcing provided by the combination of 0.9 mbar of $\mathrm{CO}_{2}$ and $\mathrm{CH}_{4}$ (i.e. $\mathrm{CO}_{2}$ and $\mathrm{CH}_{4}$ concentrations used by Rosing et al. (2010) and also tested by Charney et al. (2013)), rather than directly use $p \mathrm{CO}_{2}$ and $p \mathrm{CH}_{4}$ as boundary conditions. This was motivated because the assumption of such a low $\mathrm{CO}_{2} /$ high $\mathrm{CH}_{4}$ is likely incorrect (Dauphas and Kasting, 2011; Reinhard and Planavsky, 2011). Moreover, Rosing et al. (2010) ignored the organic haze formation $\left(\left[\mathrm{CH}_{4}\right] /\left[\mathrm{CO}_{2}\right]>0.2\right.$ (Haqq-Misra et al., 2008)). Since it makes little difference whether radiative forcing is controlled by $\mathrm{CO}_{2}$ or $\mathrm{CH}_{4}$ (Hansen et al., 1997), this approach avoids doubtful assumptions about the Archaean/Proterozoic atmosphere composition. Hence, using the present-day atmosphere as a reference, the change in net radiative flux at the tropopause $\left(\Delta F_{\text {trop }}\right.$, Fig. 1$)$ equals $19 \mathrm{~W} \mathrm{~m}^{-2}\left(\Delta F_{\text {trop }}=6\right.$ and $13 \mathrm{~W} \mathrm{~m}^{-2}$ for $0.9 \mathrm{mbar}$ of $\mathrm{CO}_{2}$ and $\mathrm{CH}_{4}$, respectively).

In addition, due to the low oxygen content of the Archean atmosphere imposed by sulfur mass independent fractionation (S-MIF) of sedimentary sulfides and sulfates $\left(10^{-5}\right.$ Present Atmospheric Level, PAL, Farquhar et al., 2001; Pavlov et al., 2000), the stratospheric ozone layer was removed in all experiments prior to $2.25 \mathrm{Ga}$ and constrained to the present-day value in other experiments. The absence of an ozone layer precluded the formation of a stratospheric temperature inversion and resulted in a $40 \mathrm{~km}$-thick atmosphere without temperature stratification (corresponding to the topmost atmospheric grid points in the AGCM). The global mean lapse rate from the surface to the $200 \mathrm{hPa}$ level was not significantly affected by the absence of the ozone layer, and only a slight mean global cooling $\left(0.7^{\circ} \mathrm{C}\right)$ was simulated at the Earth's surface (Appendix Fig. A1). Induced cooling of surface temperature $\left(1\right.$ to $\left.2{ }^{\circ} \mathrm{C}\right)$ associated with the removal of the ozone layer is in good agreement with previous studies (Kasting, 1984; Kiehl and Dickinson, 1987; Wolf magnetic data from 1 to $2.5 \mathrm{Ga}$ (Pesonen et al., 2003). 3.5 to $2.75 \mathrm{Ga}$ plate reconstructions being poorly constrained, continents were assumed to be located at low and mid latitudes. The elevation of land points was fixed at $200 \mathrm{~m}$ in all experiments. and Toon, 2013; Kunze et al., 2014).

(Godderis and Veizer, 2000) and $\delta^{34} \mathrm{~S}$ throughout the Archaean and early Proterozoic. Accordingly, the surface of the emerged continents increased from $4 \%$ at $3.5 \mathrm{Ga}$ to $27.5 \%$ at $1 \mathrm{Ga}$. Palaeogeographies were reconstructed based on paleo- 


\subsubsection{Experimental design and assumptions for clouds}

We performed sets of numerical experiments ranging from 3.5 to $1 \mathrm{Ga}$ ago with a $0.25 \mathrm{Ga}$ time increment. To avoid any effect of initial boundaries, simulations were initiated with warm conditions (present-day as starting point) and driven toward colder conditions (step-like decrease in the Sun's brightness). Each run lasted several tens of years until a steady state was reached for a decade or more. Climatic variables are averaged over the last decade.

To test the radiative impact of clouds, we considered three scenarios involving modern clouds, no cloud at all (cloud fraction fixed to 0), and clouds with large droplets (Table 1). A change in cloud droplet size affects scattering and therefore the cloud albedo (Pierrehumbert, 2010). For the parameterisation of Slingo (1989) implemented in FOAM, the cloud optical properties $\left(\mathrm{OP}_{\text {clds }}\right)$ for short-wave radiations were defined as

$\mathrm{OP}_{\text {clds }}=\mathrm{CWP}\left[a+b / r_{\mathrm{e}}\right]$,

where $a$ and $b$ are the cloud radiative coefficients (different for ice or liquid water clouds), CWP the cloud water path $\left(\mathrm{g} \mathrm{kg}^{-1}\right)$ and $r_{\mathrm{e}}$ the effective droplet radius (droplet radius affected by its distribution).

In FOAM, liquid cloud droplet radii of modern clouds vary from 5 to $10 \mu \mathrm{m}$ over landmasses and are fixed at $10 \mu \mathrm{m}$ over oceans. This distinction is made to account for enhanced cloud drop nucleation that can occur over $\mathrm{CCN}$-rich land areas. On the modern Earth, non-anthropogenic production of $\mathrm{CCN}$ is essentially related to soil dust formation, volcanic sulfate aerosols and dimethylsulfide (DMS) produced by planktonic eukaryotic algae (Charlson et al., 1987; Andreae and Rosenfield, 2008). In the absence of planktonic algae during the Archaean, the scarcity of emerged terrestrial surfaces and subaerial volcanism were considered as the possible, yet speculative, causes for the low $\mathrm{CCN}$ availability in the early Earth atmosphere (Rosing et al., 2010). To quantify the influence of large liquid droplets on climate, we ran a set of experiments in which we used the mean radius of liquid droplets of $20 \mu \mathrm{m}^{1}$ used by Rosing et al. (2010) over both the oceans and continents. Cloud droplets exceeding $15 \mu \mathrm{m}$ being rarely observed (Bréon et al., 2002), this set of simulations should be regarded as an end member. Although large liquid water droplets of $20 \mu \mathrm{m}$ diameter are expected to reduce cloud albedo (scattering effect), they also tend to rain out more rapidly (Boucher et al., 1995). According to the relationship established by Kump and Pollard (2008), the enhancement of cloud-to-precipitation rate varies as

cloud-to-precipitation rate $=\left(r_{\mathrm{e}} / r_{\mathrm{eo}}\right)^{n}$,

where $r_{\mathrm{e}}$ represents the new effective radius $(20 \mu \mathrm{m}), r_{\mathrm{eo}}$ the modern effective radius (assumed to be $10 \mu \mathrm{m}$, as oceans

\footnotetext{
${ }^{1}$ The effective radius of $20 \mu \mathrm{m}$ used by Rosing et al. (2010) was finally revised to $17 \mu \mathrm{m}$ (Goldblatt and Zahnle, 2011a).
}

cover a large fraction of the Earth's surface), and $n$ the parameter of enhanced rain-out (here $n=3$ ). The literature features a wide range of values for the enhanced rain-out parameter; here we used an intermediate value suggesting a mid-strength feedback between 1 and 5.37 (Goldblatt and Zahnle, 2011b; Penner et al., 2006; Charney et al., 2013). As the cloud lifetime cannot be changed in the absence of a cloud microphysics module, we increased the precipitable water by 8 to represent the enhanced rain-out. Albeit speculative (see Sect. 2.1), we showed that CWP fluctuations are only governed by the air moisture (Appendix Fig. A2).

\section{Results: estimating pan-glaciation thresholds}

Figure 3 shows the radiative deficit required to induce a panglaciation, the global mean surface temperature and the mean planetary albedo. It is worth emphasising that the results presented here are not representative of climate evolution over the Precambrian era because only part of the boundary conditions used are realistic (solar luminosity, palaeogeography, fraction of emerged land). Other boundary conditions including the greenhouse gas radiative forcing $\left(\Delta F_{\text {trop }}=\right.$ $+19 \mathrm{~W} \mathrm{~m}^{-2}$ ) are unrealistic. However, these were implemented in our model to allow comparison with previous simulations (Charney et al., 2013; Rosing et al., 2010) and to determine the radiative forcing threshold values required for the onset of pan-glaciations. The experiments (Exp) are labelled from 3.5 to $1 \mathrm{Ga}$ according to the boundary conditions used.

\subsection{Influence of the solar constant}

Figure $3 b$ (blue curve) represents the global mean surface temperature (Ts) simulated using the present-day cloud parameterisation. Ts is as low as $-75^{\circ} \mathrm{C}$ in $\operatorname{Exp}(3.5 \mathrm{Ga})$ and increases linearly up to $-65^{\circ} \mathrm{C}$ in $\operatorname{Exp}(2.5 \mathrm{Ga})$. The planetary albedo always exceeds 0.65 (Fig. 3c, blue curve) when the Earth is ice covered. An abrupt change, expressed by a shift of both temperature and albedo, is observed between $\operatorname{Exp}(2.5 \mathrm{Ga})$ and $\operatorname{Exp}(2.25 \mathrm{Ga})$. In $\operatorname{Exp}(2.25 \mathrm{Ga})$, Ts reaches $-20^{\circ} \mathrm{C}$ and the albedo drops to 0.45 . This corresponds to a partially frozen Earth where sea ice spreads up to $30^{\circ}$ latitude in both hemispheres. Between $\operatorname{Exp}(2.25 \mathrm{Ga})$ and $\operatorname{Exp}(1.75 \mathrm{Ga})$, a slight global warming of about $5^{\circ} \mathrm{C}$ is observed, followed by a marked change of some $24^{\circ} \mathrm{C}$ between $\operatorname{Exp}(1.75 \mathrm{Ga})$ and $\operatorname{Exp}(1.25 \mathrm{Ga})$, and a final slight warming of $4{ }^{\circ} \mathrm{C}$ between $\operatorname{Exp}(1.25 \mathrm{Ga})$ and $\operatorname{Exp}(1 \mathrm{Ga})$.

From these experiments, three climate states can be defined; a snowball Earth between $\operatorname{Exp}(3.5 \mathrm{Ga})$ and $\operatorname{Exp}(2.5 \mathrm{Ga})$, a partially frozen Earth between $\operatorname{Exp}(1.75 \mathrm{Ga})$ and $\operatorname{Exp}(2.25 \mathrm{Ga})$, and a weakly frozen Earth between $\operatorname{Exp}(1 \mathrm{Ga})$ and $\operatorname{Exp}(1.25 \mathrm{Ga})$. Although the solar brightness increased sub-linearly between 3.5 and $1 \mathrm{Ga}$, the global mean surface temperature changed dramatically during this time 
a)
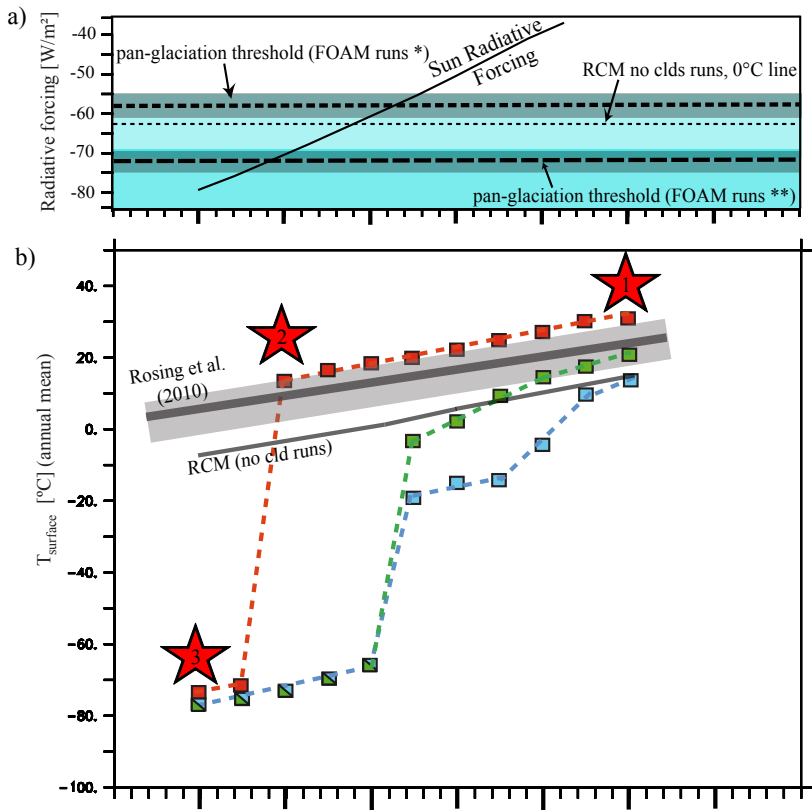

c)

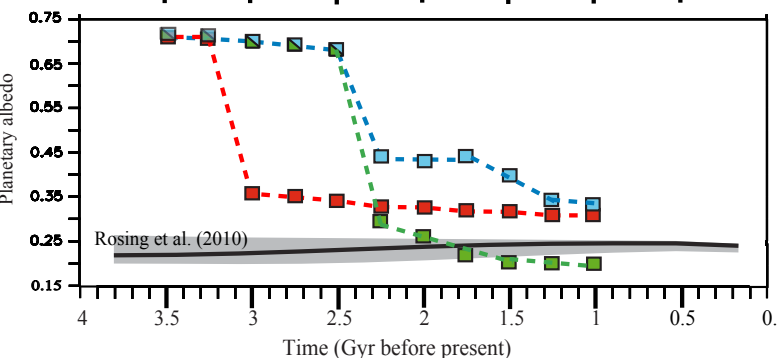

d)

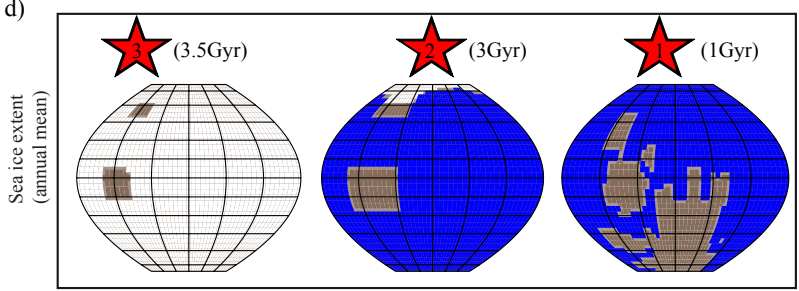

Fig. 3. 3-D climate simulations from 3.5 to $1 \mathrm{Ga}$ with a greenhouse radiative forcing by $\mathrm{CO}_{2}$ and $\mathrm{CH}_{4}$ fixed to $19 \mathrm{~W} \mathrm{~m}^{-2}$ ( $\Delta F_{\text {trop; }}$ see Fig. 1). (a) Radiative deficit required for the onset of a pan-glaciation with RCM (no cloud runs, surface albedo fixed to 0.264 ), FOAM runs (* modern clouds and cloud-free runs and ** large-droplet clouds $(20 \mu \mathrm{m}))$. Grey lines represent uncertainties related to temporal resolution $(0.25 \mathrm{Ga})$. (b) Evolution of surface temperature versus time assuming increasing irradiance and linear continental growth (see Fig. 2). Grey line is from Rosing et al. (2010). Blue and red curves were obtained using liquid droplet sizes of 5 to $10 \mu \mathrm{m}$ (modern clouds) and $20 \mu \mathrm{m}$ (clouds with large droplets), respectively. Green squares represent the cloud-free scenario. (c) Evolution of planetary albedo versus time ( $\alpha_{\text {ocean }} 0.06$, $\alpha_{\text {rocky desert continents }} 0.32, \alpha_{\text {seaice }} 0.5, \alpha_{\text {snow }} 0.8$ ). (d) Red stars represent sea ice extent (white) predicted with runs performed with large $(20 \mu \mathrm{m})$ droplets (Fig. 3b, c shows the corresponding temperature/albedo). period (Fig. 3b). Between 1 and $1.25 \mathrm{Ga}$, the solar brightness is high enough to restrict the sea ice capping to the high latitudes $\left(\sim 60^{\circ}\right)$ and to bring the equator-pole surface temperature gradient to the present-day level. Between $\operatorname{Exp}(1.25 \mathrm{Ga})$ and $\operatorname{Exp}(1.75 \mathrm{Ga})$, sea ice spreads towards the equator up to $30^{\circ}$ of latitude due to the reduced incoming solar radiation. Between $\operatorname{Exp}(1.75 \mathrm{Ga})$ and $\operatorname{Exp}(2.25 \mathrm{Ga})$, the sea ice maximum extent remains located in the vicinity of the tropics. This is due to a latitudinal gradient of temperature two times higher than in the $\operatorname{Exp}(1 \mathrm{Ga})$, which arises from a strong meridional energy transport by the atmosphere and oceans. For a solar constant lower than $1148 \mathrm{~W} \mathrm{~m}^{-2}(2.25 \mathrm{Ga})$, the solar brightness is low enough to drive climate towards snowball Earth conditions. Hence, for a fixed greenhouse-gas concentration of $\Delta F_{\text {trop }}=+19 \mathrm{~W} \mathrm{~m}^{-2}$, the solar constant evolution and its interplay with the ice-albedo feedback appear as the predominant factor governing the Earth's climate. This contrast with the RCM results (Fig. 3a) where the albedo is held constant at 0.264 (Goldblatt and Zahnle, 2011b) due to the absence of the ice-albedo feedback.

\subsection{Influence of continental surfaces}

A lower surface albedo due to a reduced continental area $\left(\alpha_{\text {bare soil }}=0.32, \alpha_{\text {ocean }}=0.06\right)$ has been suggested as a solution to the FYSP (Schatten and Endel, 1982; Rosing et al., 2010; but see Walker et al., 1982 and Golbatt and Zanhle, 2011, for a controversy). No-cloud experiments show that the planetary albedo, which corresponds to the surface albedo, fluctuates with the growth of sea ice (Fig. 3b, green curve). Using the amount of energy reaching the Earth (expressed by $F=S / 4(1-\alpha)$, with $\Delta \alpha=0.10$ and $S=1148 \mathrm{~W} \mathrm{~m}^{-2}$ ), we estimated the radiative forcing induced by the ice-albedo feedback to $-29 \mathrm{~W} \mathrm{~m}^{-2}$ (cooling effect) between 1 and $2.25 \mathrm{Ga}$. This calculation shows that a slight change in the sea ice surface $\left(\alpha_{\text {sea-ice }}=0.6\right)$ can easily overcome the influence of a smaller continental area on the surface albedo $\left(\alpha_{\text {bare soil }}=0.32, \alpha_{\text {ocean }}=0.06\right)$. These results demonstrate that the surface albedo is mainly governed by the sea ice extension, the growth of continental surfaces being a second-order factor. This conclusion is to challenged when the climate-carbon cycle feedbacks will be considered (Walker et al., 1981; Godderis and Veizer, 2000) (see companion paper).

\subsection{Influence of clouds}

Cloud experiments performed at $1 \mathrm{Ga}$ show that the cloud radiative forcing is equal to -10 and $-20 \mathrm{~W} \mathrm{~m}^{-2}$ at high and mid-latitudes, respectively (Fig. 4b). Accordingly, the absence of clouds seems to limit the sea ice spreading at high latitudes and to prevent the increase in the planetary albedo (Fig. 3c). This mechanism can explain why cloudfree experiments result in a warmer climate than those using modern clouds (Fig. 3b, green curve). Surprisingly, the shift 

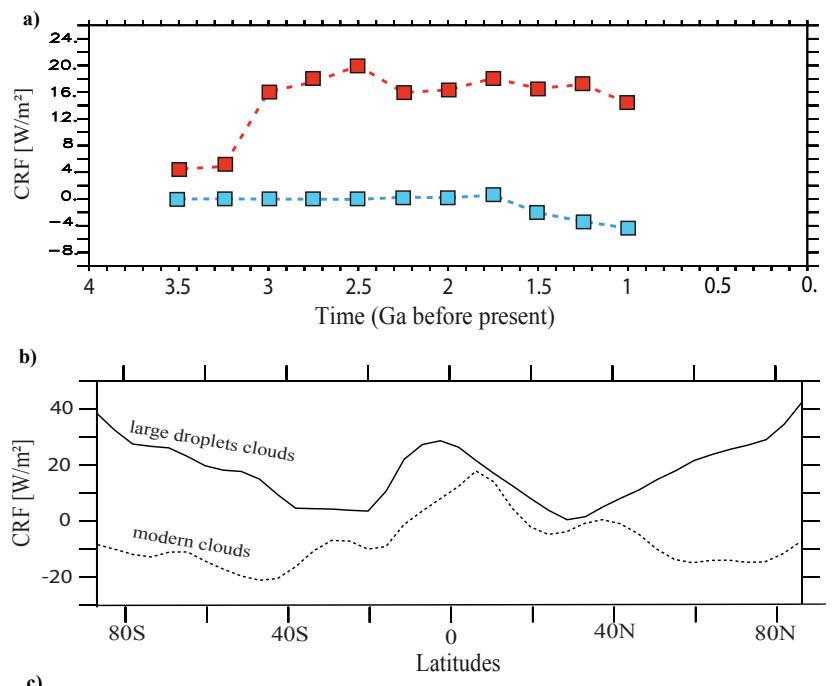

c)

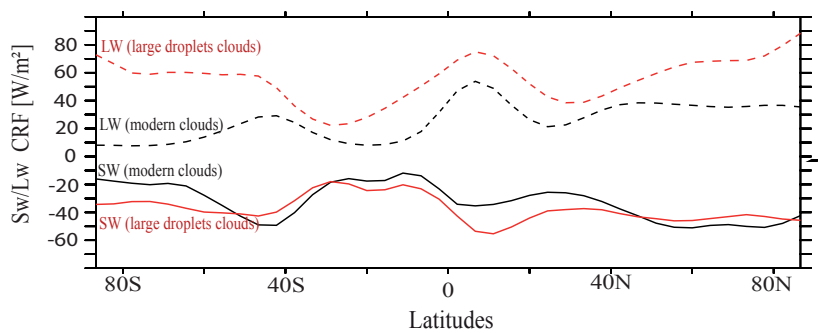

Fig. 4. (a) Net cloud radiative forcing (CRF, unit $\mathrm{W} \mathrm{m}^{-2}$ ) versus time. Blue squares represent runs with modern clouds. Largedroplet clouds (red squares) result in a positive forcing because the effect of infrared trapping overcomes that of scattering. (b) CRF as a function of latitude for simulations performed at $1 \mathrm{Ga}$. The black line represents large-droplet clouds and the dashed line the modern cloud parameterisation. (c) Simulations performed using $1 \mathrm{Ga}$ boundary conditions. Dashed lines represent long-wave (LW) budget of clouds (greenhouse effect), continuous lines their short-wave budget (albedo effect).

from a snowball state toward a partially ice-free Earth occurs between 2.5 and $2.25 \mathrm{Ga}$ in both types of experiments. However, this apparent synchronicity is due to the relatively long duration increment of $250 \mathrm{Ma}$ used between experiments. Since the incoming solar energy varies by as much as $5 \mathrm{~W} \mathrm{~m}^{-2}$ between 2.5 and $2.25 \mathrm{Ga}$ (Fig. 2), it is not possible to evaluate with precision when the pan-glaciation occurs. In addition, it cannot be excluded that in a cold climate environment, the cloud scheme of FOAM underestimates the cloud radiative forcing (Abbot et al., 2012).

\subsection{Effects of the cloud droplet size}

The use of large liquid droplets $(20 \mu \mathrm{m})$ increases the global mean surface temperature by about 20 to $35^{\circ} \mathrm{C}$ compared to present-day droplet sizes (Fig. 3, red curves). In the largedroplet experiments, the shift towards snowball state occurs between 3 and $3.25 \mathrm{Ga}$ with a mean global surface temper- ature of $13{ }^{\circ} \mathrm{C}$. In contrast, modern clouds experiments result in a non-snowball state at $2.25 \mathrm{Ga}$ with a mean global surface temperature of $-19^{\circ} \mathrm{C}$. To explain why large-droplet experiments are in contrast to modern cloud simulations, we examined how clouds affect the Earth's budget. The cloud radiative forcing (CRF) obtained with large droplets was positive in all experiments (Fig. 4a). As an example, in the $1 \mathrm{Ga}$ run, a net CRF of $14 \mathrm{~W} \mathrm{~m}^{-2}$ was obtained using large droplets instead of $-4 \mathrm{~W} \mathrm{~m}^{-2}$ for modern cloud simulation, a result in agreement with Goldblatt and Zahnle (2011b). In detail, clouds with large droplets generate a positive CRF at high latitudes $\left(+40 \mathrm{~W} \mathrm{~m}^{-2}\right)$, preventing sea ice formation (Fig. 4b). Inhibiting sea ice formation limits the ice-albedo feedback efficiency and maintains the planetary albedo at low values (Fig. 3c, red curve). This change in CRF results from the combination of a slightly lower negative CRF at short wavelength (scattering effect) and a much higher positive CRF at large wavelength (IR trapping; Fig. 4c). As a consequence, even low-elevation clouds (the most reflective clouds) yield a positive CRF, as already shown by Goldblatt and Zahnle (2011b). The increase in evaporation due to warmer oceans enhances the cloud water content. This mechanism increases in turn the greenhouse effect because it amplifies the cloud emissivity $\left(\varepsilon_{\mathrm{cld}}\right)$ expressed as

$\varepsilon_{\mathrm{cld}}=1-e^{(-D * \mathrm{Kabs} * \mathrm{CWP})}$,

where $D$ is a diffusivity factor (1.66), Kabs is the longwave absorption coefficient $\left(\mathrm{m}^{2} \mathrm{~g}^{-1}\right)$ and CWP is the cloud liquid water path.

\section{Resolution of the faint young Sun problem: sensitivity tests}

Fixing the change in the net radiative flux at the tropopause to $19 \mathrm{~W} \mathrm{~m}^{-2}$ (Fig. 1), none of the experiments can prevent the onset of pan-glaciation. The Earth's surface temperature threshold before shifting into a snowball Earth varies from $-19^{\circ} \mathrm{C}$, using modern clouds, to $+13^{\circ} \mathrm{C}$, using large-droplet clouds. The estimated radiative deficit required for the onset of a pan-glaciation between $-57.5 \pm 2.5$ and $-72 \pm 2.5 \mathrm{~W} \mathrm{~m}^{-2}$ results in a threshold value between $21.5 \pm 2.5$ and $6.5 \pm 2.5 \mathrm{~W} \mathrm{~m}^{-2}$, respectively, to solve the FYSP (Fig. 3a). In the following, several warming parameters (greenhouse gas concentrations, ice albedo, a faster rotation rate and/or saltier oceans) able to generate an early Archaean climate at least as warm as today are tested at about $3.5 \mathrm{Ga}$.

\subsection{Effects of greenhouse gases and ice albedo}

Assuming a solar constant of $1053 \mathrm{~W} \mathrm{~m}^{-2}$ (77\% of the present-day value), an idealised geography, no ozone layer and two different cloud parameterisations (modern clouds and clouds with large droplets), the radiative forcing was enhanced either by increasing the concentrations of greenhouse 
Table 2. Resolutions of the Faint Young Sun Problem: sensitivity tests (Sect. 4.1).

\begin{tabular}{|c|c|c|c|c|c|c|c|}
\hline $\begin{array}{c}\text { set of } \\
\text { simulations }\end{array}$ & $\begin{array}{l}\text { Boundary } \\
\text { conditions }\end{array}$ & $\begin{array}{c}p \mathrm{CO}_{2} \\
\left(10^{-3} \text { bar }\right)\end{array}$ & $\begin{array}{c}p \mathrm{CH}_{4} \\
\left(10^{-6} \text { bar }\right)\end{array}$ & $\begin{array}{l}\text { Ice albedo } \\
\text { Vis/nIR }\end{array}$ & $\begin{array}{c}\Delta F_{\text {trop }} \\
\left(\mathrm{W} \mathrm{m}^{-2}\right)\end{array}$ & $\begin{array}{l}\text { Droplet size } \\
\quad(\mu \mathrm{m})\end{array}$ & $\begin{array}{c}\text { Global Ts } \\
\left({ }^{\circ} \mathrm{C}\right)\end{array}$ \\
\hline Run1 & $3.5 \mathrm{Ga}$ & 2.4 & 300 & $0.7 / 0.5$ & +24 & 20 & 14.2 \\
\hline Run2 & “" & 25.2 & 1.7 & “ & +34 & “ & 18.5 \\
\hline Run3 & “ & 16.8 & “ & “ & +30 & “ & 15.7 \\
\hline Run4 & 6 & 25.2 & “ & “ & +34 & $5-10$ & -73 \\
\hline Run5 & “ & 56.0 & “ & “ & +41 & 66 & 15.5 \\
\hline Run6 & “ & 112.0 & “ & “ & +49 & “ & 21.1 \\
\hline Run7 & “ & 25.2 & 66 & $0.5 / 0.5^{*}$ & +34 & “ & -10.5 \\
\hline
\end{tabular}

* Visible snow albedo fixed to 0.7 (instead of 0.9 ).

gases $\left(p \mathrm{CO}_{2}\right.$ and/or $\left.p \mathrm{CH}_{4}\right)$ or by reducing the ice albedo from 0.6 to 0.5 (e.g. Warren et al., 2002). A summary of the simulations and global mean surface temperatures is given in Table 2.

When clouds with large droplets are considered, a radiative forcing at the tropopause $\left(\Delta F_{\text {trop }}\right)$ of $+24 \mathrm{~W} \mathrm{~m}^{-2}$ yields an Earth surface temperature not significantly different from its present-day value $\left(14.2^{\circ} \mathrm{C}\right)$. Such a radiative forcing, which corresponds to 2.4 mbar of $\mathrm{CO}_{2}$ and 0.3 mbar of $\mathrm{CH}_{4}$, is able to solve the FYSP (Fig. 1). These results, which are in agreement with Charney al. (2013), and support the hypothesis defended by Rosing et al. (2010), are strongly dependent on the boundary conditions used. As an example, considering a modern $p \mathrm{CH}_{4}$, the $p \mathrm{CO}_{2}$ required to maintain a warm climate is about 16.8 mbar (run3, Table 2). When both $\mathrm{PCH}_{4}$ and droplet sizes are fixed to their modern values, a $p \mathrm{CO}_{2}$ of 56 mbar is required to simulate a mean temperature of $15^{\circ} \mathrm{C}$ (run5, Table 2). In addition, ice albedo represents another factor that can affect the FYSP. When reducing the ice albedo by 0.1 , the model simulates a colder climate, although the equator region remains ice free (run 7, Table 2). Climate response to varying ice albedo suggests the need for a good treatment of sea ice (notably for the sea ice dynamics), and also explains why the calculated greenhouse gas concentrations required for solving the FYSP are model dependent, most of them using different values for ice albedo $(0.65$ for LMDz; Charney et al., 2013, 0.68 (visible) to 0.3 (nearIR) for CAM3; Wolf and Toon, 2013, and 0.5-0.75 for EMAC, Kunze et al., 2014).

\subsection{Effects of faster Earth rotation rate and saltier oceans}

Palaeozoic rhythmites, mollusc shells and coral fossil records indicate that the Earth rotated faster in the deep past leading to a shorter Length Of the Day (LOD) (Walker and Zahnle, 1986). Between 3.8 and $2.5 \mathrm{Ga}$, the LOD increased from 14 to $18 \mathrm{~h}$. Jenkins (1993a) and Jenkins et al. (1993) tested the effects of a shorter LOD on the early Earth climate using an atmospheric GCM coupled to a swamp ocean. He demonstrated that a faster rotation (corresponding to a LOD of $\sim 14 \mathrm{~h}$ ) reduces the mean global cloudiness by $20 \%$ and increases the mean global surface temperature by $2{ }^{\circ} \mathrm{C}$. In fact this global warming hides local temperature changes, namely a cooling at the poles and a warming at the tropics due to the weakening of transient eddies carrying the heat from low to high latitudes. Hence, faster Earth rotation may have caused the climate to be more sensitive to the ice-albedo feedback (Kienert et al., 2012). To check this assumption, we ran a set of experiments assuming a LOD of $16 \mathrm{~h}(\sim 3.5 \mathrm{Ga})$. Another peculiar feature of the Archaean Earth is the occurrence of saltier oceans. Knauth (2005) suggested a long-term decline in ocean salinity throughout the Precambrian in parallel with the development of sedimentary basins and climatic conditions able to form and preserve halite $(\mathrm{NaCl})$ deposits. As a consequence, the salinity of Archaean oceans may have been close to $60 \%$ (in comparison with $35 \%$ at the present-day) (Knauth, 2005; Foriel et al., 2004). Because a higher salinity lowers the seawater freezing temperature (Millero and Poisson, 1981), sea ice formation could have been delayed, potentially reducing the influence of the ice-albedo feedback. Since the atmospheric GCM FOAM is coupled with a slab ocean, a higher salinity cannot be taken into account. To mimic saltier oceans, we fixed the seawater freezing point at $-3.3{ }^{\circ} \mathrm{C}$ following the equation of state of seawater proposed by Millero and Poisson (1981). Note that heat diffusion in our mixed-layer ocean was not adjusted in the Earth's rotation rate and salinity experiments (Table 3 ).

Accounting for saltier oceans, FOAM simulates a warming at high latitudes (Fig. 5), restricting sea ice formation and reducing the Earth's sensitivity to the ice-albedo feedback. More intriguing is the response induced by a faster Earth rotation. In present-day conditions, a change in day length from 24 to $16 \mathrm{~h}$ causes a global mean surface warming of about $2^{\circ} \mathrm{C}$ (from 14.5 to $16.3^{\circ} \mathrm{C}$, Appendix Fig. A1), in agreement with previous results (Jenkins, 1993b). However, the warming is not homogeneous. Due to the reduced latitudinal heat transport and change in the cloud pattern, a faster Earth rotation warms up low latitudes but cools down high latitudes (Appendix Fig. A1), the warming of low latitudes overcoming the cooling of high latitudes. However, 
Table 3. Simulations carried out with a $\Delta F_{\text {trop }}=+24 \mathrm{~W} \mathrm{~m}^{-2}$ (Sect. 4.2). Note that heat diffusion in our mixed-layer ocean was not adjusted in the rotation rate and salinity experiments.

\begin{tabular}{|c|c|c|c|c|c|c|}
\hline \multirow{2}{*}{$\begin{array}{l}\text { set of } \\
\text { simulations }\end{array}$} & \multicolumn{2}{|c|}{ Boundary conditions } & \multirow{2}{*}{$\begin{array}{c}\text { LOD } \\
\text { (hours) }\end{array}$} & \multirow{2}{*}{$\begin{array}{l}\text { Droplet } \\
\operatorname{size}(\mu \mathrm{m})\end{array}$} & \multirow{2}{*}{$\begin{array}{l}\text { Seawater } \\
\text { freezing }\end{array}$} & \multirow{2}{*}{$\begin{array}{c}\text { Mean surface } \\
\text { temperature }\end{array}$} \\
\hline & Paleogeography Solar & constant & & & & \\
\hline Standard conditions & $3.5 \mathrm{Ga}$ & $1053 \mathrm{~W} \mathrm{~m}^{-2}$ & 24 & 20 & $-1.8^{\circ} \mathrm{C}$ & $14.2^{\circ} \mathrm{C}$ \\
\hline Saltier ocean & 66 & 6 & 24 & 66 & $-3.3^{\circ} \mathrm{C}$ & $15.0^{\circ} \mathrm{C}$ \\
\hline Faster Rotation & 6 & 6 & 16 & “ & $-1.8^{\circ} \mathrm{C}$ & $14.2^{\circ} \mathrm{C}$ \\
\hline Early Earth & “ & 6 & 16 & “ & $-3.3^{\circ} \mathrm{C}$ & $14.4^{\circ} \mathrm{C}$ \\
\hline
\end{tabular}

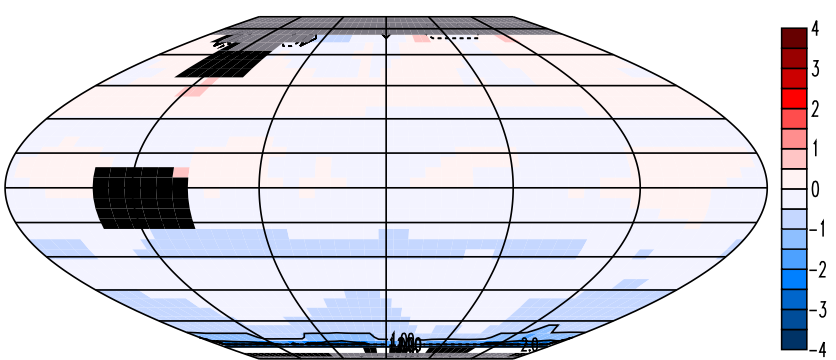

Annual SST anomalies $\left[{ }^{\circ} \mathrm{C}\right]$ Faster Rotation - Standard

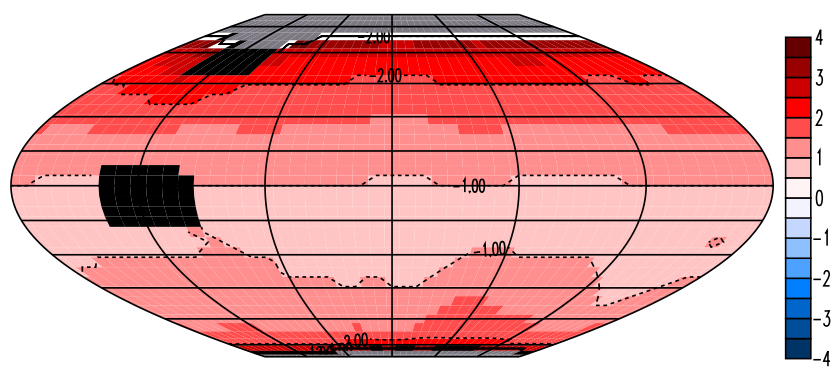

Annual SST anomalies $\left[{ }^{\circ} \mathrm{C}\right]$

Saltier ocean - Standard

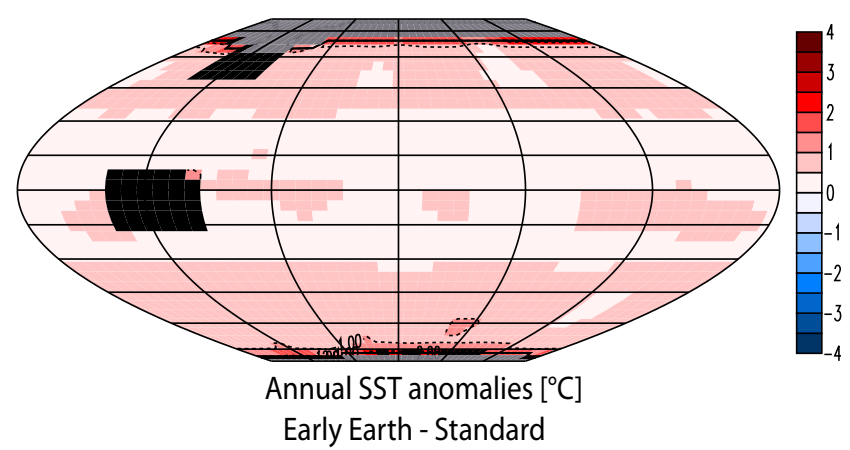

Fig. 5. Sea surface temperature anomalies $(\triangle \mathrm{SST})$ as a result of a faster Earth rotation rate $(\mathrm{LOD}=16 \mathrm{~h})$ and/or saltier ocean. Simulations performed with $3.5 \mathrm{Ga}$ boundary conditions with largedroplet clouds and a $\Delta F_{\text {trop }}=+24 \mathrm{~W} \mathrm{~m}^{-2}$ (standard conditions). The saltier ocean experiment uses standard conditions associated with an ocean two times saltier; the faster rotation experiment has a length of day of $16 \mathrm{~h}$; the early Earth experiment combines both. in colder conditions, a shorter LOD leads to the opposite trend: the sea ice formation at high and mid latitudes is facilitated, increasing the albedo and amplifying the cooling (Fig. 5). Consequently, when both a shorter LOD and saltier oceans are considered, their effects are balanced (a shorter LOD increases the Earth's sensitivity to the ice-albedo feedback while saltier oceans reduce it). This explains why these processes do not affect the solution of the FYSP (Fig. 5). It is noteworthy that our faster rotation simulation agrees with LMDz, but not CLIMBER (Kienert et al., 2012). One of the main reasons for such a difference is discussed below.

\section{Discussion}

FOAM, like other atmospheric GCMs, relies on a physical basis, which means that mechanisms and feedbacks are explicitly accounted for. Goldblatt and Zahnle (2011b) challenged the use of GCMs given that sub-grid scale parameterisation of clouds in these models precludes their use in palaeoclimate modelling. Here, we discuss differences between AGCMs and other categories of climate models (RCMs and EMIC) and argue that AGCMs are relevant and accurate tools for investigating deep-time climates.

\subsection{FYSP resolutions: FOAM versus CLIMBER (EMIC)}

FOAM results largely disagree with CLIMBER (Kienert et al., 2012, 2013). For instance, using CLIMBER, Kienert et al. $(2012,2013)$ suggested that a $p \mathrm{CO}_{2}$ of 0.6 bar is required to generate a mean global temperature of $15^{\circ} \mathrm{C}$ (for a $3.8 \mathrm{Ga}$ solar constant of $1023 \mathrm{~W} \mathrm{~m}^{-2}$ ) and that a faster rotation rate strongly impacts the ice-albedo feedback. This is at odd with the results obtained with FOAM in the present study. One of the reasons why CLIMBER yields opposite results to atmospheric GCMs essentially because of the different lapse rate parameterisation. Kienert et al. (2013) used Outgoing Longwave Radiation in clear-sky diagnostic (OLR) to check the validity of longwave radiative transfer, fixing the thermal structure of the atmosphere according to the lapse rate given in Halevy et al. (2009). However, they omitted to quantify OLR fluctuations caused by CLIMBER lapse rate parameterisation. As shown by Pierrehumbert (2004), the lapse rate 


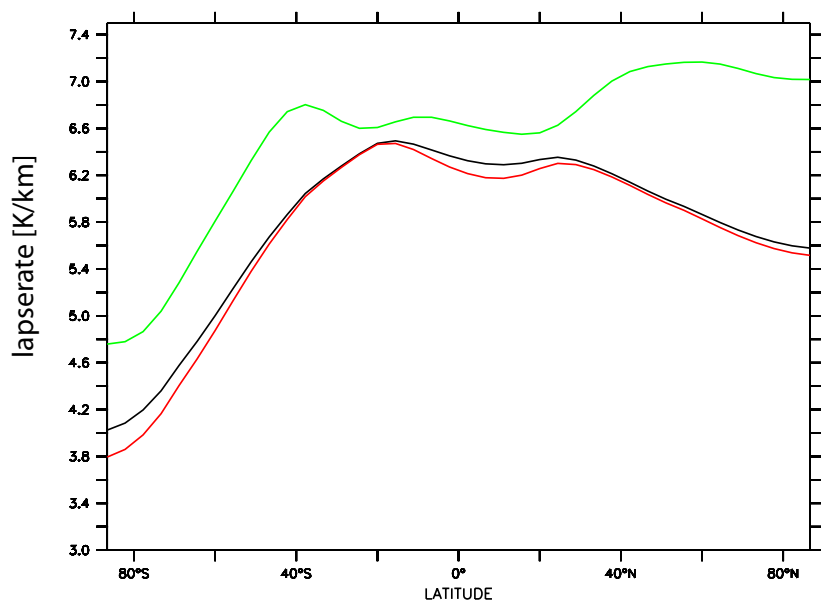

Fig. 6. Lapse rates (annual mean) calculated by CLIMBER lapse rate formula and FOAM using $1 \mathrm{Ga}$ conditions (no clouds). Black curve represents the standard formulation in CLIMBER (Petoukhov et al., 2000), the red line is the calculation adapted for a faster rotation in CLIMBER (Kienert et al., 2012, 2013). The green line represents the FOAM lapse rate.

governs the sensitivity of climate to $\mathrm{CO}_{2}$ so that the greenhouse effect $(G)$ is expressed as

$G\left(\mathrm{~W} \mathrm{~m}^{-2}\right)=\sigma \mathrm{Ts}^{4}-\mathrm{OLR}$,

where Ts is the surface temperature $(\mathrm{K}), \sigma$ the StefanBoltzmann constant. OLR corresponds to the energy lost by the Earth as infrared radiation at the top of the atmosphere.

The CLIMBER lapse rate is based on a theoretical approach (Petoukhov et al., 2000) and was developed to fit empirical data such as

lapse rate $=\Gamma_{0}+\Gamma_{1}(\mathrm{Ts}-273.16 \mathrm{~K}) *\left(1-a_{\mathrm{q}} * Q^{2}\right)$

$$
-\Gamma_{2} * n_{\mathrm{cld}}
$$

where $\Gamma_{0}, \Gamma_{1}$ and $\Gamma_{2}$ are lapse rate parameters $\left(\Gamma_{0}\right.$ $=5.2 \times 10^{-3} \mathrm{~K} \mathrm{~m}^{-1}, \quad \Gamma_{1}=5.5 \times 10^{-5} \mathrm{~K} \mathrm{~m}^{-1}, \quad \Gamma_{2}=$ $\left.10^{-3} \mathrm{~K} \mathrm{~m}^{-1}\right), Q$ is the surface-specific humidity $\left(\mathrm{kg} \mathrm{kg}^{-1}\right)$, $n_{\text {cld }}$ the cumulus cloud amount and $a_{\mathrm{q}}=10^{3}(\mathrm{~kg} \mathrm{~kg})^{-2}$. Kienert et al. $(2012,2013)$ updated this formula to account explicitly for a faster Earth rotation rate such as $\Gamma_{0}=5.1 \times 10^{-3} \mathrm{~K} \mathrm{~m}^{-1}, \quad \Gamma_{1}=6.1 \times 10^{-5} \mathrm{~K} \mathrm{~m}^{-1}, \Gamma_{2}=$ $0.9^{-3} \mathrm{~K} \mathrm{~m}^{-1}$ and $a_{\mathrm{q}}=1.171 \times 10^{3}(\mathrm{~kg} \mathrm{~kg})^{-2}$. To illustrate CLIMBER lapse rate parameterisation better, we used FOAM outputs (i.e. Ts and $Q$ ). To suppress the cloud effects, we extracted outputs from a run performed at $1 \mathrm{Ga}$ with no clouds; therefore $n_{\text {cld }}$ is fixed to 0 (lapse rates computed with clouds are available in Appendix Fig. A3). In CLIMBER the radiative transfer depends on $\mathrm{Ht}$ (troposphere height), so we calculated lapse rates for the entire troposphere (from the Earth's surface to an atmospheric pressure level of 254 mbar).

Figure 6 shows lapse rates for different case scenarios: (1) with the standard formula implemented in CLIMBER
(Petoukhov et al., 2000), (2) using the adapted formula in case of a faster rotation (Kienert et al., 2012, 2013) and (3) using FOAM. For the same values of Ts and $Q$, we show that the lapse rate is systematically underestimated with CLIMBER, hence inducing warmer temperature and a higher thermal radiation flux loss at the tropopause (the unusual shape of the lapse rate is explained by the northern hemisphere which is almost entirely oceanic, see Fig. 2b). Therefore, for the same $p \mathrm{CO}_{2}$, CLIMBER results in a less efficient greenhouse effect. This artefact in the CLIMBER lapse rate explains why this EMIC needs such a large $p \mathrm{CO}_{2}$ when a present-day Earth rotation is considered (Kienert at al., 2012). The required $p \mathrm{CO}_{2}$ is even higher when a faster Earth rotation is imposed. Although the authors discussed the uncertainties linked to CLIMBER radiative module (Kienert et al., 2013), they omitted lapse rate/OLR interplays. In addition to possible effects of ocean and sea ice dynamics and an ice albedo above classical values, this omission could explain why Kienert et al. $(2012,2013)$ proposed such a high $p \mathrm{CO}_{2}$ to solve the FYSP.

\subsection{Pan-glaciation thresholds and ice-albedo feedback: AGCMs versus RCMs}

It is noteworthy that atmospheric GCMs are able to maintain a large fraction of open oceans (i.e. above the seawater freezing point) with very moderate amounts of greenhouse gases, 0.9 mbar of $\mathrm{CO}_{2}$ and $\mathrm{CH}_{4}$ for $\mathrm{LMDz}(3.8 \mathrm{Ga}$ ), $3.7 \mathrm{mbar}$ of $\mathrm{CO}_{2}$ for EMAC $(3.5 \mathrm{Ga})$ and $5 \mathrm{mbar}$ of $\mathrm{CO}_{2}$ for CAM3 $(2.7 \mathrm{Ga})$, a result that contrasts with RCM estimates (0.04 bar of $\mathrm{CO}_{2}$ at $3.5 \mathrm{Ga}$, Kasting, 1987). RCMs assume that a drop of the mean temperature below $0^{\circ} \mathrm{C}$ leads to a runaway glaciation, and therefore induces high $p \mathrm{CO}_{2}$ in order to maintain ice-free oceans during the Archaean. However, stable climates have been simulated using AGCMs while the global mean surface temperature falls well below $0{ }^{\circ} \mathrm{C}$ (Charney et al., 2013; Wolf and Toon, 2013; Kunze et al., 2014, this study). Wolf and Toon (2013) suggested that the difference in the temperature leading to a runaway glaciation was the reason for the high estimates of $p \mathrm{CO}_{2}$ by RCMs.

To better understand why RCMs are not able to calculate the threshold temperature allowing the onset of runaway glaciations, we implemented an albedo dependency on temperature in the RCM developed by MacKay and Khalil (1991). It should be noted that Wang and Stone (1980) incorporated this process, but for unknown reasons, all RCM experiments kept a surface albedo held constant. This lack had biased the climate response and the Earth was maintained unfrozen for unrealistic reasons. To represent the icealbedo feedback, we used the formula given by Pierrehumbert et al. (2011) where the Earth albedo is assumed to be

- Ice-free for $T>T_{0}=20^{\circ} \mathrm{C}$, with an albedo $\left(\alpha_{0}\right)=0.2$

- Totally ice covered for $T<T_{\text {freeze }}$, with an albedo $\left(\alpha_{\text {freeze }}\right)=0.6$ 


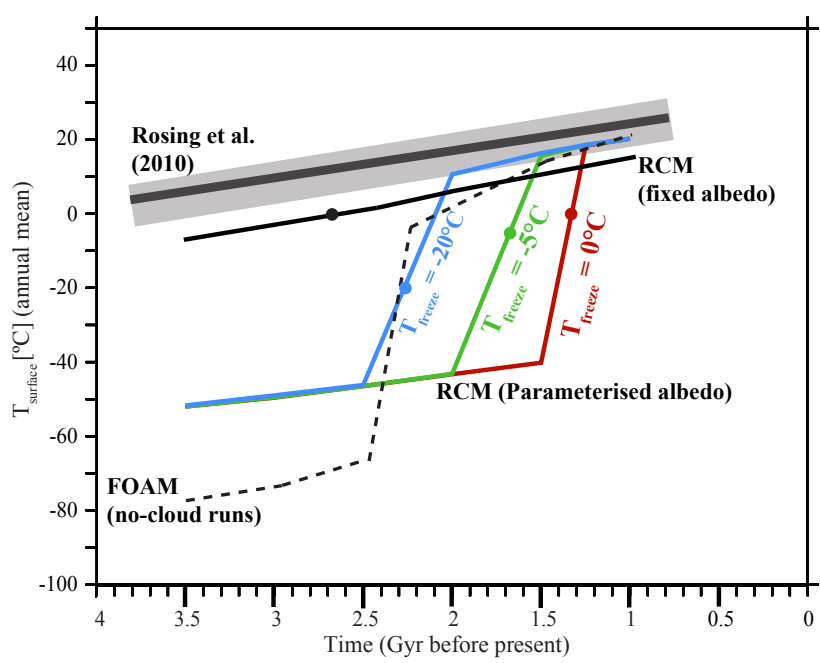

Fig. 7. RCM simulations showing the evolution of the surface temperature versus time between 3.5 and $1 \mathrm{Ga}$, with and without the ice-albedo feedback, and assuming increasing irradiance in the absence of clouds and a greenhouse radiative forcing of $19 \mathrm{~W} \mathrm{~m}^{-2}$. Blue, green and red curves were obtained using the ice-albedo feedback formula from Pierrehumbert et al. (2011) where $T_{\text {freeze }}$ values $\left(-20^{\circ} \mathrm{C},-5^{\circ} \mathrm{C}, 0{ }^{\circ} \mathrm{C}\right)$ represent the freezing temperature for the Earth (snowball Earth threshold). The black curve is obtained using a surface albedo fixed at 0.264 (absence of ice-albedo feedback). Rosing et al. (2010) and FOAM runs are described in Fig. 3.

- Partially ice covered for $T_{\text {freeze }}<T<T_{0}$, the albedo is interpolated according to the formula:

$\alpha(T)=\alpha_{\mathrm{o}}+\left(\alpha_{\text {freeze }}-\alpha_{\mathrm{o}}\right)\left[\left(T-T_{0}\right)^{2} /\left(T_{\text {freeze }}-T_{0}\right)^{2}\right]$

where $T$ is the Earth's temperature and $T_{\text {freeze }}$ is the threshold temperature for the onset on global glaciations. The difference between $T_{\text {freeze }}$ and $T_{0}$ is a measure of the meridional temperature gradient and therefore represents the efficiency of latitudinal heat transport. Because Wolf and Toon (2013) proposed that the freezing temperature is the main factor explaining differences between RCMs and AGCMs, we tested several $T_{\text {freeze }}$ values $\left(-20^{\circ} \mathrm{C},-5^{\circ} \mathrm{C}, 0^{\circ} \mathrm{C}\right)$. To avoid the difficulty of figuring out how to represent cloud changes between FOAM and RCM we removed clouds, so that the albedo corresponds to the planetary albedo incorporating the effects of Rayleigh scattering, atmospheric solar absorption and the reflective properties of the surface.

The RCM and FOAM are forced with the same boundary conditions, that is a net radiative forcing of $+19 \mathrm{~W} \mathrm{~m}^{-2}$ and no clouds. In the absence of the ice-albedo feedback $(\alpha=0.264)$, the RCM simulates a linear increase in the mean temperature through time, the threshold value of $0^{\circ} \mathrm{C}$ (supposed to represent the threshold temperature for runaway glaciations) being reached at about $2.6 \mathrm{Ga}$ (Fig. 7). In contrast, RCM experiments that include the ice-albedo feedback show a drastic shift in the evolution of the mean temperature through time, similar to the one observed in FOAM experiments. More interestingly, when the ice-albedo feedback is parameterised such as the threshold temperature for the onset of snowball Earth $\left(T_{\text {freeze }}\right)$ equals $-20^{\circ} \mathrm{C}$, the timing of the shift from snowball Earth to ice-free conditions is similar in RCM and FOAM experiments. This similarity occurs because RCM mimics the latitudinal air surface temperature gradient of FOAM $\left(\Delta T=40^{\circ} \mathrm{C}\right.$ from equator to $45^{\circ}$ of latitudes - sea ice latitudes). This calculation illustrates an essential weakness of RCM: their inability to calculate $T_{\text {freeze }}$ in the absence of latitudinal heat transport. In AGCMs, $T_{\text {freeze }}$ varies with the prescribed boundary conditions (for example in FOAM, the maximum latitudinal extent of the ice cap before the shift to runaway glaciation varies from $30^{\circ}$ to $45^{\circ}$ and $70^{\circ}$ for experiments using modern clouds, cloud-free, and large-droplet clouds, respectively). This extent is controlled by the change in ocean heat flux, a process which cannot be captured by RCMs. Faster rotation and saltier oceans also slightly affect $T_{\text {freeze }}$. Consequently, AGCMs, in contrast to RCMs, more faithfully represent the ice-albedo feedback and hence the climatic transition towards snowball Earth.

\subsection{Pan-glaciation thresholds and ice-albedo feedback: FOAM versus other AGCMs}

The recent use of atmospheric GCMs for investigating the FYSP offered a great opportunity to compare FOAM with CAM3 (Wolf and Toon, 2013) LMDz (Charney et al., 2013) and EMAC (Kunze et al., 2014). All these studies suggested that Earth is less prone to full glaciations. Using a $2.7 \mathrm{Ga}$-old solar constant of $1093 \mathrm{~W} \mathrm{~m}^{-2}$ and $1 \mathrm{mbar}$ of $\mathrm{CO}_{2}$ and $\mathrm{CH}_{4}$ (other parameters being held at present-day values), CAM3 simulates a mean surface temperature close to $2^{\circ} \mathrm{C}$ (Wolf and Toon, 2013). For the same conditions, FOAM yields a full glaciation. A small difference in ice albedo of 0.68 (vis) $/ 0.3$ (nearIR) with CAM3 and 0.7(vis)/0.5(nearIR) with FOAM seems to explain the different behaviour. Although minor, this difference has important consequences on the impact of the ice-albedo feedback when Earth becomes ice-covered (ice line spreads down to $30-40^{\circ}$; run 7 of Table 2). Using a $3 \mathrm{Ga}$-old solar constant $\left(1082 \mathrm{~W} \mathrm{~m}^{-2}\right)$ and $0.9 \mathrm{mbar}$ of $\mathrm{CO}_{2}$, LMDz does not simulate a full glaciation (Charney et al., 2013). This behaviour arises from both the prescribed boundary conditions and heat transport. Charney et al. (2013) made the hypothesis that Earth was an aquaplanet at $3 \mathrm{Ga}$. In such conditions, LMDz simulates larger amount of water vapour, which enhances heat transport to high latitudes and decreases the equator-pole temperature gradient, so that the ice-albedo feedback becomes less efficient and the runaway glaciation is delayed. This result is in good agreement with the result of Kunze et al. (2014) who also assumed a water-covered world for the early Archaean ( $3.5 \mathrm{Ga}$, solar constant $1046 \mathrm{~W} \mathrm{~m}^{-2}$ ). Using EMAC, they showed that it was possible to get a stable ice-free ocean at low latitudes (surface temperature equals to $-9^{\circ} \mathrm{C}$ ) with moderate $\mathrm{CO}_{2}$ concentrations $(3670 \mathrm{ppmv})$. 
For comparison, $\mathrm{LMDz}$ prevents the early Earth $(3.8 \mathrm{Ga}$, $1025 \mathrm{~W} \mathrm{~m}^{-2}$ ) from completely freezing with a greenhouse forcing corresponding to 0.9 mbar of a $\mathrm{CO}_{2}$ combined to 0.9 mbar of $\mathrm{CH}_{4}$ (Charney et al., 2013).

LMDz simulations also investigated the effect of CCN. Performing simulations with larger droplets (droplet radius set to 17 instead of $20 \mu \mathrm{m}$ in our study), Charney et al. (2013) suggested a strong impact on the terrestrial radiative budget, in agreement with this study. More interestingly, both AGCMs simulate an increase in the cloud water path in lowaltitude clouds located at high latitudes. Since the use of these two different cloud schemes shows similar behaviour, we suspect that the warming driven by high-latitude clouds inhibiting sea ice formation is not model dependent (see Sect. 3.4).

Other processes such as pressure broadening of $\mathrm{CO}_{2}$ and $\mathrm{H}_{2} \mathrm{O}$ by high atmospheric pressure (Goldblatt et al., 2009) or high concentrations of $\mathrm{H}_{2}$ (Wordsworth and Pierrehumbert, 2013), which are not treated here, could also warm up the early Earth and affect the FYSP solutions. In addition, several processes are missing in this study, which are potential sources of uncertainties. The use of a slab ocean, with heat transport parameterised through diffusion, precludes the faithful representation of the meridional ocean heat transport. Indeed, during the Archaean the oceanic heat transport should supposedly be enhanced due to the smaller land fraction (Endal and Schatten, 1982). We also acknowledge that saltier oceans possibly lead to a weaker overturning (Williams et al., 2010). These conflicting assessments concerning ocean circulation, and their respective influence on the FYSP, could be explored using a fully coupled dynamic ocean model, an investigation which has not been conducted here. The last limitation relative to the use of a slab ocean is the absence of sea ice dynamics, which tends to slow the sea ice flow (Voigt and Abbot, 2012). This lack may change the radiative deficit triggering the onset of pan-glaciation and underestimate the greenhouse gas concentrations required to keep the early Earth unfrozen.

Obviously atmospheric GCMs still have limitations (Hack, 1998; Abbot et al., 2012; Stevens and Bony, 2013) and results can slightly differ according to their respective parameterisations or boundary conditions. However, as fully dynamic models, AGCMs represent a powerful tool for improving our understanding of deep past Earth climates, capturing cloud mechanisms involved in global warming, as well as time-dependent factors (e.g. palaeogeography, rotation rate). However, constraints on paleo- $p \mathrm{CO}_{2}$ gained from climate modelling studies cannot be directly compared to geological data because all these studies omit to consider the carbon cycle-climate equilibrium. To estimate more accurately $p \mathrm{CO}_{2}$ and the Earth's surface temperature evolution, we associated the atmospheric GCM simulations discussed in this paper with a geochemical model to investigate the carbon cycle climate during the Archaean (see companion paper).

\section{Conclusions}

FOAM, like other AGCMs, suggests a faint young Sun problem less problematic than initially assumed and solves the FYSP with a composition of greenhouse gases one order a magnitude lower than RCM or EMIC. Accounting for a $23 \%$ weaker Sun at $3.5 \mathrm{Ga}$, we show that a moderate radiative forcing of $41 \mathrm{~W} \mathrm{~m}^{-2}$ is sufficient to maintain the mean global surface temperature close to its present-day value. Assuming a high $p \mathrm{CH}_{4}$ in the Archaean atmosphere (Pavlov et al., 2000; Catling et al., 2007), we show that such a moderate radiative forcing can be provided by the combination of 1 (0.3) mbar of methane and 11.5 (16) mbar of carbon dioxide. The presence of large-droplet clouds can theoretically provide significant warming so that lower $\mathrm{CO}_{2}$ and $\mathrm{CH}_{4}$ partial pressures are required for the maintenance of an ice-free surface. We demonstrated, however, that such changes in cloud properties cannot alone provide sufficient warming to solve the FYSP with low ( 0.9 mbar) $p \mathrm{CO}_{2}$ as defended by Rosing et al. (2010).

This study highlights the central role of AGCMs over RCMs in investigating glacial thresholds. RCMs overestimate the early Archaean $p \mathrm{CO}_{2}$ (i.e. $0.2-0.3$ bar) required to keep equatorial waterbelts ice free due to their inability to calculate the correct threshold mean temperature for the onset of full glaciation (i.e. $\left.T_{\text {freeze }}\right)$. Applying Archaean boundary conditions, our AGCM simulations show a wide range of possible values for $T_{\text {freeze }}$, from -20 to $13^{\circ} \mathrm{C}$, according to the latitudinal temperature gradient. In contrast, RCMs use a fixed $T_{\text {freeze }}$ value $\left(0^{\circ} \mathrm{C}\right.$, the freezing point of seawater) and therefore inaccurately estimate the poleward heat transport. The weak sensitivity of CLIMBER to $\mathrm{CO}_{2}$ could be explained by its lapse rate calculation, which overestimates the energy leaving the Earth as infrared radiation. Our AGCM supports the main conclusions arising from previous AGCMs, but predicts an early Earth more inclined to full glaciation. Higher ice albedo is a likely cause for the stronger ice-albedo feedback in FOAM compared to CAM3. LMDz and EMAC simulate warmer climate due to a weaker ice-albedo feedback inherited from the absence of continents, a boundary condition that enhances poleward moist heat fluxes. However, all these studies cannot simulate ocean and sea ice dynamics, a limitation which may underestimate the greenhouse gas concentrations required to keep the early Earth unfrozen. Following this step forward in the understanding of physical processes able to solve the FYSP, we now consider carbon cycle-climate interplays to provide a complete picture of the faint young Sun problem (companion paper).

Acknowledgements. We thank the two anonymous referees for their very insightful reviews which considerably improved the quality of the manuscript, and the editorial board for the quality of the review procedure. This work was granted access to the HPC resources of CCRT under allocation 2014-017013 made 
by GENCI (Grand Equipement National de Calcul Intensif). This work was supported by ANR eLIFE2 and LabexUnivEarth (ANR-10-LABX-0023 and ANR-11-IDEX-0005-02). This is IPGP contribution 3494.

Edited by: M. Claussen

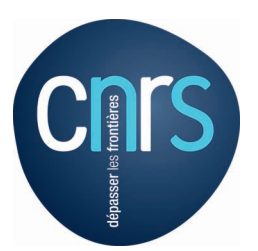

The publication of this article is financed by CNRS-INSU.

\section{References}

Abbot, D. S., Voigt, A., Branson, M., Pierrehumbert, R. T., Pollard, D., Le Hir, G., and Koll, D. D. B.: Clouds and snowball Earth deglaciation, Geophys. Res. Lett., 39, L20711, doi:10.1029/2012GL052861, 2012.

Andreae, M. O. and Rosenfeld, D.: Aerosol-cloudprecipitation interactions. Part 1. The nature and sources of cloud-active aerosols, Earth-Sci. Rev., 89, 13-41, doi:10.1016/j.earscirev.2008.03.001, 2008.

Boucher, O., Le Treut, H., and Baker, M. B.: Precipitation and radiation modeling in a general circulation model: Introduction of cloud microphysical processes, J. Geophys. Res., 100, 1639516414, doi:10.1029/95JD01382, 1995.

Bréon, F. M., Tanré, D., and Generoso, S.: Aerosol Effect on Cloud Droplet Size Monitored from Satellite, Science, 295, 834-838, doi:10.1126/science.1066434, 2002.

Catling, D. C., Claire, M. W., and Zahnle, K. J.: Anaerobic methanotrophy and the rise of atmospheric oxygen, Phil. Trans. R. Soc., 365, 1867-1888, doi:10.1098/rsta.2007.2047, 2007.

Charlson, R. J., Lovelock, J. E., Andreae, M. O., and Warren, S. G.: Oceanic Phytoplankton, atmospheric sulfur, cloud albedo and climate, Nature, 326, 655-661, 1987.

Charney, B., Forget, F., Wordworth, R., Leconte, J., Millour, E., Codron, F., and Spiga, A.: Exploring the faint young Sun problem and the possible climates of the Archean Earth with a 3-D GCM, J. Geophys. Res., 118, 10414-10431, doi:10.1002/jgrd.50808, 2013.

Dauphas, N. and Kasting, J. F.: Low $p \mathrm{CO}_{2}$ in the pore water, not in the Archean air, Nature, 474, E2-E3, doi:10.1038/nature09960, 2011.

Driese, S. G., Jirsa, M. A., Ren, M., Brantley, S. L., Sheldon, N. D., Parker, D., and Schmitz, M.: Neoarchean paleoweathering of tonalite and metabasalt: implicationsq for reconstructions of $2.69 \mathrm{Ga}$ early terrestrial ecosystems and paleoatmospheric chemistry, Precambrian Res., 187, 1-17, doi:10.1016/j.precamres.2011.04.003, 2011.

Farquhar, J., Airieau, S., and Thiemens, M. H.: Observation of wavelength-sensitive mass-independent sulfur isotope effects during $\mathrm{SO}_{2}$ photolysis: Implications for the early atmosphere, J. Geophy. Res.-Planets, 106, 32829-32839, 2001.
Feulner, G.: The faint young sun problem, Rev. Geophys., 50, RG2006, doi:10.1029/2011RG000375, 2012.

Foriel, J., Philippot, P., Rey, P., Somogyi, A., Banks, D., and Menez, B.: Biological control of $\mathrm{Cl} / \mathrm{Br}$ and low sulfate concentration in a 3.5-Gyr-old seawater from North Pole, Western Australia, Earth Planet. Sci. Lett., 228, 451-463, 2004.

Godderis, Y. and Veizer, J.: Tectonic control of chemical and isotopic composition of ancient oceans: the impact of continental growth, Am. J. Sci., 300, 434-461, 2000.

Goldblatt, C. and Zahnle, K. J.: Faint Young Sun Paradox remains, Nature, 474, E1, doi:10.1038/nature09961, 2011 a.

Goldblatt, C. and Zahnle, K. J.: Clouds and the Faint Young Sun Paradox, Clim. Past, 7, 203-220, doi:10.5194/cp-7-203-2011, $2011 b$.

Goldblatt, C., Claire, M. W., Lenton, T. M., Matthews, A. J., Watson. A. J., and Zahnle, K. J.: Nitrogen-enhanced greenhouse warming on early Earth, Nat. Geosci., 2, 891-896, doi:10.1038/NGEO692, 2009.

Gough, D. O.: Solar interior structure and luminosity variations, Sol. Phys., 74, 21-34, 1981.

Hack, J. J.: Sensitivity of the simulated climate to a diagnostic formulation for cloud liquid water, J. Climate, 11, 1497-1515, 1998.

Halevy, I., Pierrehumbert, R. T., and Schrag, D. P.: Radiative transfer in $\mathrm{CO}_{2}$-rich paleoatmospheres, J. Geophys. Res., 114, D18112, doi:10.1029/2009JD011915, 2009.

Hansen, J., Sato, M., and Ruedy, R.: Radiative Forcing and climate response, J. Geophys. Res., 102, 6831-6864, 1997.

Haqq-Misra, J. D., Domagal-Goldman, S. D., Kasting, P. J., and Kasting, J. F.: A revised, hazy methane greenhouse for the archean Earth, Astrobiology, 8, 1127-1137, 2008.

Jacob, R.: Low frequency variability in a simulated atmosphere ocean system, PhD Thesis, University of Wisconsin-Madison, 1997-310, 1997.

Jenkins, G. S.: The effects of reduced land fraction and solar forcing on the general circulation results from the NCAR CCM, Glob. Planet. Change, 7, 321-333, 1993a.

Jenkins, G. S.: A General Circulation Model Study of the Effects of Faster Rotation Rate, Enhanced $\mathrm{CO}_{2}$ Concentration, and Reduced Solar Forcing' Implications for the Faint Young Sun Paradox, J. Geophys. Res., 98, 20803-20811, 1993 b.

Jenkins, G. S., Marshall, H. G., and Kuhn, W. R.: Precambrian climate - the effects of land area and Earth's rotation rate, J. Geophys. Res.-Atmos., 98, 8785-8791, doi:10.1029/93JD00033, 1993.

Kasting, J. F.: The evolution of the prebiotic atmosphere, Origins Life Evol. B., 14, 75-82, 1984.

Kasting, J. F.: Theoretical constraints on oxygen and carbon-dioxide concentrations in the Pre-cambrian atmosphere, Precambrian Res., 34, 205-229, 1987.

Kasting, J. F.: Early Earth faint young sun redux, Nature, 464, 687689, 2010.

Kiehl, J. T. and Dickinson, R. E.: A study of the radiative effects of enhanced atmospheric $\mathrm{CO}_{2}$ and $\mathrm{CH}_{4}$ on early Earth surface temperatures, J. Geophys. Res.-Atmos., 92, 2991-2998, 1987.

Kienert, H., Feulner, G., and Petoukhov, V.: Faint young sun problem more severe due to ice-albedo feedback and higher rotation rate of the early Earth, Geophys. Res. Lett., 39, L23710, doi:10.1029/2012GL054381, 2012. 
Kienert, H., Feulner, G., and Petoukhov, V.: Albedo and heat transport in 3-D model simulations of the early Archean climate, Clim. Past, 9, 1841-1862, doi:10.5194/cp-9-1841-2013, 2013.

Knauth, L. P.: Temperature and salinity history of the Precambrian ocean: implications for the course of microbial evolution, Palaeogeogr. Palaeocl., 219, 53-69, 2005.

Kump, L. R. and Pollard, D.: Amplification of cretaceous warmth by biological cloud feedbacks, Science, 320, 195-195, 2008.

Kunze, M., Godolt, M., Langematz, U., Grenfell, J. L., HamannReinus, A., and Rauer, H.: Investigating the early Earth faint young Sun problem with a general circulation model, Planet. Space Sci., doi:10.1016/j.pss.2013.09.011, in press, 2014.

Le Hir, G., Donnadieu, Y., Krinner, G., and Ramstein, G.: Toward the snowball earth deglaciation, Clim. Dynam., 35, 285-297, 2010.

Lowe, D. R. and Tice, M. M.: Tectonic controls on atmospheric, climatic, and biological evolution 3.5-2.5 Ga, Precambrian Res., 158, 177-197, 2007.

MacKay, R. M. and Khalil, M. A. K.: Theory and Development of a One Dimensional Time Dependant Radiative Convective Climate Model, Chemosphere, 22, 383-417, 1991.

Millero, F. J. and Poisson, A.: International one-atmosphere equation of state of seawater, Deep-Sea Res. Pt. I, 28, 625-629, 1981.

Pavlov, A. A., Kasting, J. F., Brown, L. L., Rages, K. A., and Freedman, R.: Greenhouse warming by $\mathrm{CH}_{4}$ in the atmosphere of early Earth, J. Geophys. Res.-Planets, 105, 11981-11990, 2000.

Penner, J. E., Quaas, J., Storelvmo, T., Takemura, T., Boucher, O., Guo, H., Kirkevåg, A., Kristjánsson, J. E., and Seland, Ø.: Model intercomparison of indirect aerosol effects, Atmos. Chem. Phys., 6, 3391-3405, doi:10.5194/acp-6-3391-2006, 2006.

Petoukhov, V., Ganopolski, A., Brovkin, V., Claussen, M., Eliseev, A., Kubatzki, C., and Rahmstorf, S.: CLIMBER-2: a climate system model of intermediate complexity. Part I: model description and performance for present climate, Clim. Dynam. 16, 1-17, doi:10.1007/PL00007919, 2000.

Pesonen, L. J., Elming, S. A, Mertanen, S., Pisarevsky, S., D’Agrella-Filho, M. S., Meert, J. G., Schmidt, P. W., Abrahamsen, N., and Bylund, G.: Palaeomagnetic configuration of continents during the Proterozoic, Tectonophysics, 375, 289-324, 2003.

Pierrehumbert, R. T.: High levels of atmospheric carbon dioxide necessary for the termination of global glaciation, Nature, 429, 646-649, 2004.

Pierrehumbert, R. T.: Principles of Planetary Climate, Cambridge University Press, 652 pp., 2010.

Pierrehumbert, R. T., Abbot, D. S., Voigt., A., and Koll, D.: Climate of the Neoproterozoic Annual, Rev. Earth Planet. Sci., 39, 417460, doi:10.1146/annurev-earth-040809-152447, 2011.

Reinhard, C. T. and Planavsky, N. J.: Mineralogical constraints on Precambrian $p \mathrm{CO}_{2}$, Nature, 474, E1-E2, doi:10.1038/nature09959, 2011.
Rosing, M. T., Bird, D. K., Sleep, N. H., and Bjerrum, C. J.: No climate paradox under the faint early Sun, Nature, 464, 744-747, doi:10.1038/nature08955, 2010.

Rye, R., Kuo, P. H., and Holland, H. D.: Atmospheric carbondioxide concentrations before 2.2-billion years ago, Nature, 378, 603-605, 1995.

Sagan, C. and Mullen, G.: Earth and Mars - evolution of atmospheres and surface tempera-tures, Science, 177, 52-56, doi:10.1126/science.177.4043.52, 1972.

Schatten, K. H. and Endal, A. S.: The faint young Sun climate paradox - volcanic influence, Geophys. Res. Lett., 9, 1309-1311, doi:10.1029/GL009i012p01309, 1982.

Sheldon, N. D.: Precambrian paleosols and atmospheric $\mathrm{CO}_{2}$ levels, Precambrian Res., 147, 148-155, 2006.

Slingo, A.: A GCM parameterization for the shortwave radiative properties of water clouds, J. Atmos. Sci., 46, 1419-1427, 1989.

Stevens, B. and Bony, S.: What Are Climate Models Missing?, Science, 340, 1053-1054, doi:10.1126/science.1237554, 2013.

Voigt, A. and Abbot, D. S.: Sea-ice dynamics strongly promote Snowball Earth initiation and destabilize tropical sea-ice margins, Clim. Past, 8, 2079-2092, doi:10.5194/cp-8-2079-2012, 2012.

von Paris, P., Rauer, H., Grenfell, J. L., Patzer, B., Hedelt, P., Stracke, B., Trautmann, T., and Schreier, F.: Warming the early earth- $\mathrm{CO}_{2}$ reconsidered, Planet. Space Sci., 56, 1244-1259 doi:10.1016/j.pss.2008.04.008, 2008.

Walker, J. C. G.: Climatic factors on the Archean Earth, Palaeogr. Palaeocl., 40, 1-11, doi:10.1016/0031-0182(82)90082-7, 1982.

Walker, J. C. G. and Zahnle, K. J. Lunar nodal tide and distance to the Moon during the Pre-cambrian, Nature, 320, 600-602, 1986.

Walker, J. C. G., Hays, P. B., and Kasting, J. F.: A Negative Feedback Mechanism For The Long-Term Stabilization of Earth's Surface-Temperature, J. Geophys. Res.-Ocean. Atmos., 86, 9776-9782, 1981

Wang, W. and Stone, P. H.: Effect of Ice-Albedo Feedback on Global Sensitivity in a One-Dimensional Radiative-Convective Climate Model, J. Atmophs. Sci., 37, 545-552, 1980.

Warren, S. G., Brandt, R. E., Grenfell, T. C., and McKay, C. P.: Snowball Earth: Ice thickness on the tropical ocean, J. Geophys. Res.-Ocean., 107, 31-1-31-18, doi:10.1029/2001JC001123, 2002.

Williams, P. D., Guilyardi, E., Madec, G., Gualdi, S., and Scoccimarro, E.: The role of mean ocean salinity in climate, Dynam. Atmos. Oceans, 49, 108-123, doi:10.1016/j.dynatmoce.2009.02.001, 2010.

Wolf, E. T. and Toon, O. B.: Hospitable Archean Climates Simulated by a General Circulation Model, Astrobiology, 13, 656673, doi:10.1089/ast.2012.0936, 2013.

Wordsworth, R. and Pierrehumbert, R.: Hydrogen-nitrogen greenhouse warming in Earth's early atmosphere, Science, 339, 64-67, doi:10.1126/science.1225759, 2013. 


\section{Appendix A}

a)

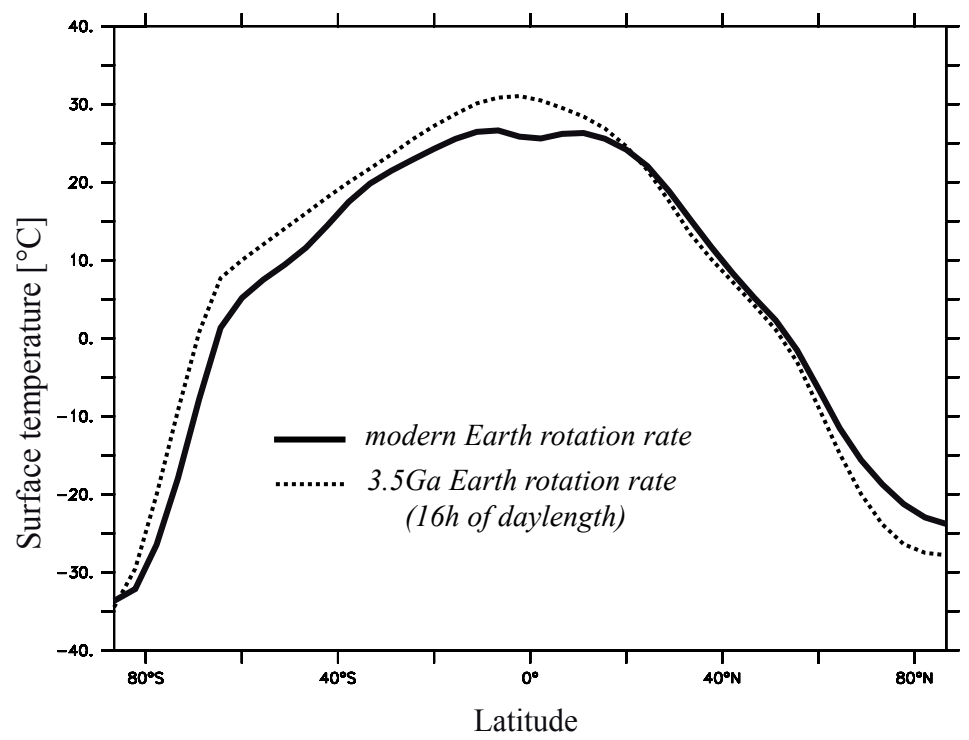

b)

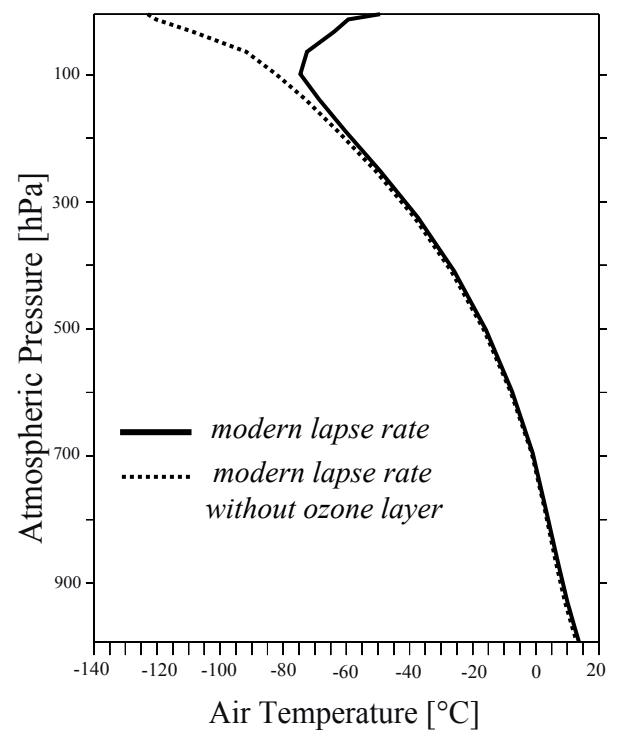

Fig. A1. (a) Temperature gradient as a function of Earth rotation rates. (b) Atmospheric lapse rate as a function of ozone layer presence/removal. Simulations performed under present-day boundary conditions. 


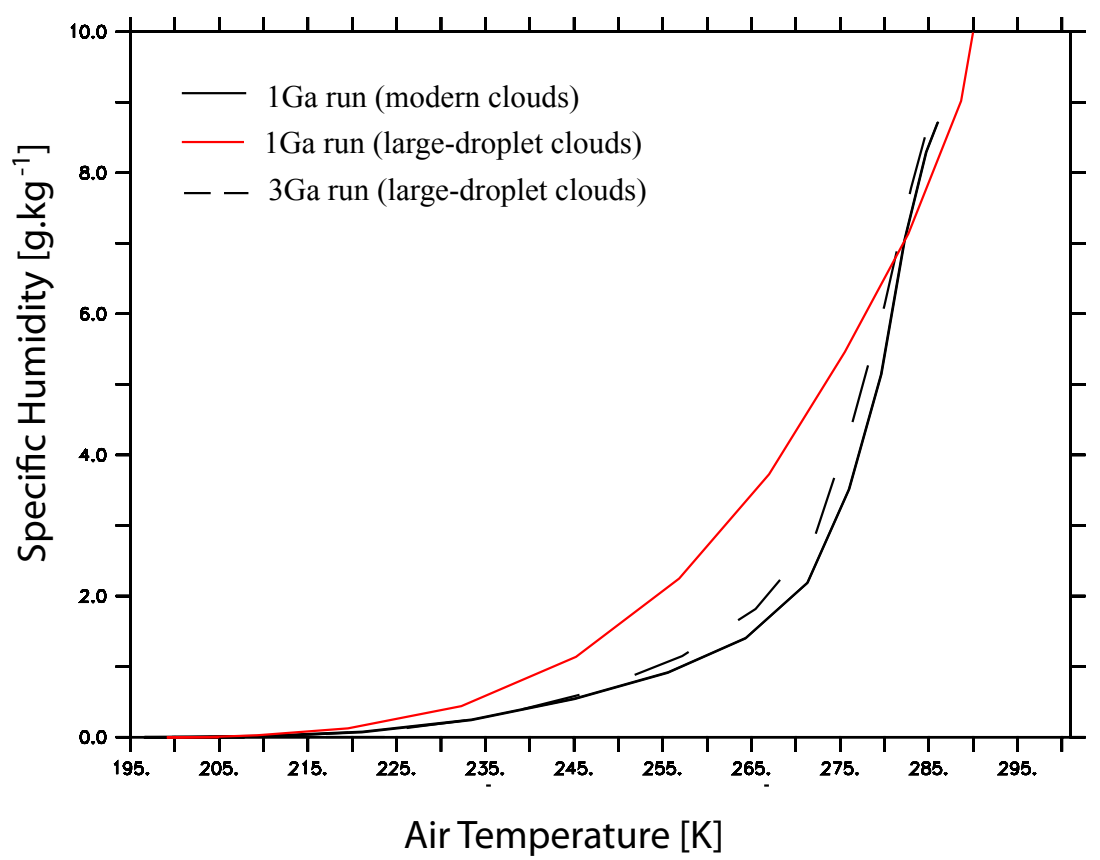

Fig. A2. Specific humidity response to varying air temperature. The Earth's global temperature equals $12.9^{\circ} \mathrm{C}\left(1 \mathrm{Ga}\right.$, modern clouds), $30.4^{\circ} \mathrm{C}$ (1 Ga, large-droplet clouds) and $12.3^{\circ} \mathrm{C}(1 \mathrm{Ga}$, large-droplet clouds). 


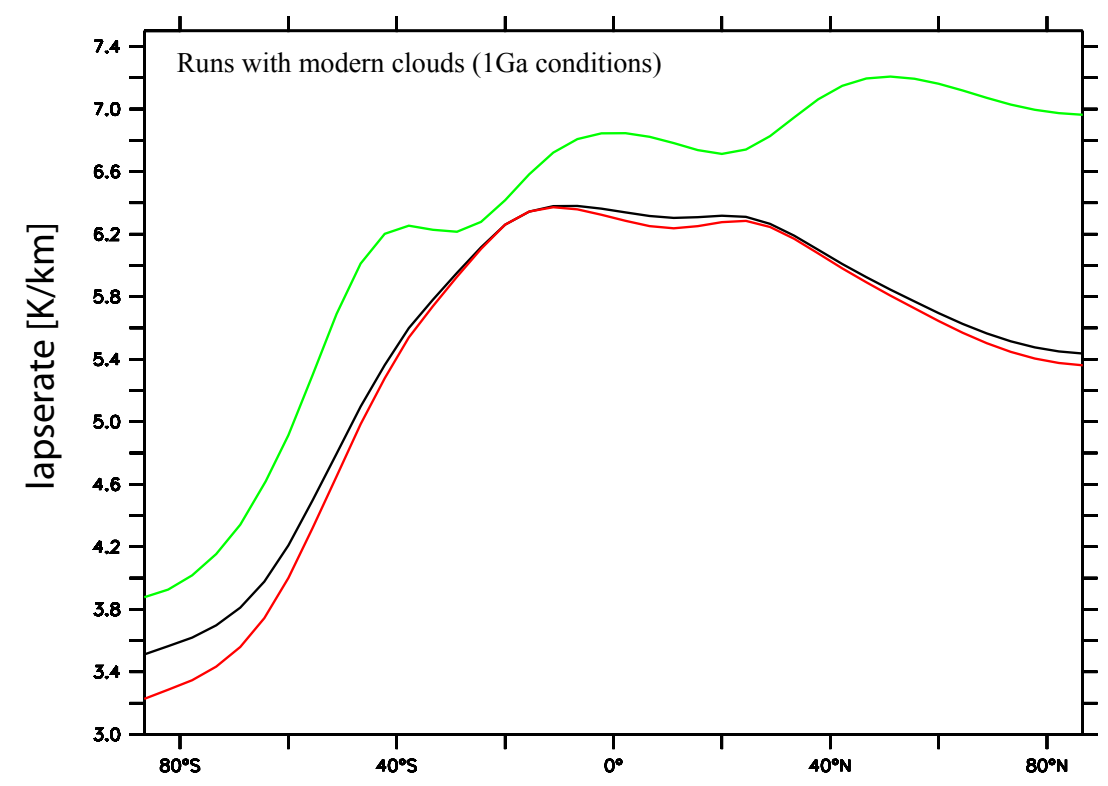

Fig. A3. Lapse rates (annual mean) using $1 \mathrm{Ga}$ boundary conditions (modern clouds parameterization), calculated by the CLIMBER lapse rate formula and FOAM using the same conditions. Black curve represents the standard formulation in CLIMBER (Petoukhov et al., 2000), the red line is the calculation adapted for a faster rotation in CLIMBER (Kienert et al., 2012, 2013). The green line represents the FOAM lapse rate. 